\title{
Tailored Materials for High Efficiency CIDI Engines (CAT)
}

Final Report for CRADA

No. PNNL/272 with

Caterpillar, Inc.

G Grant

S Jana

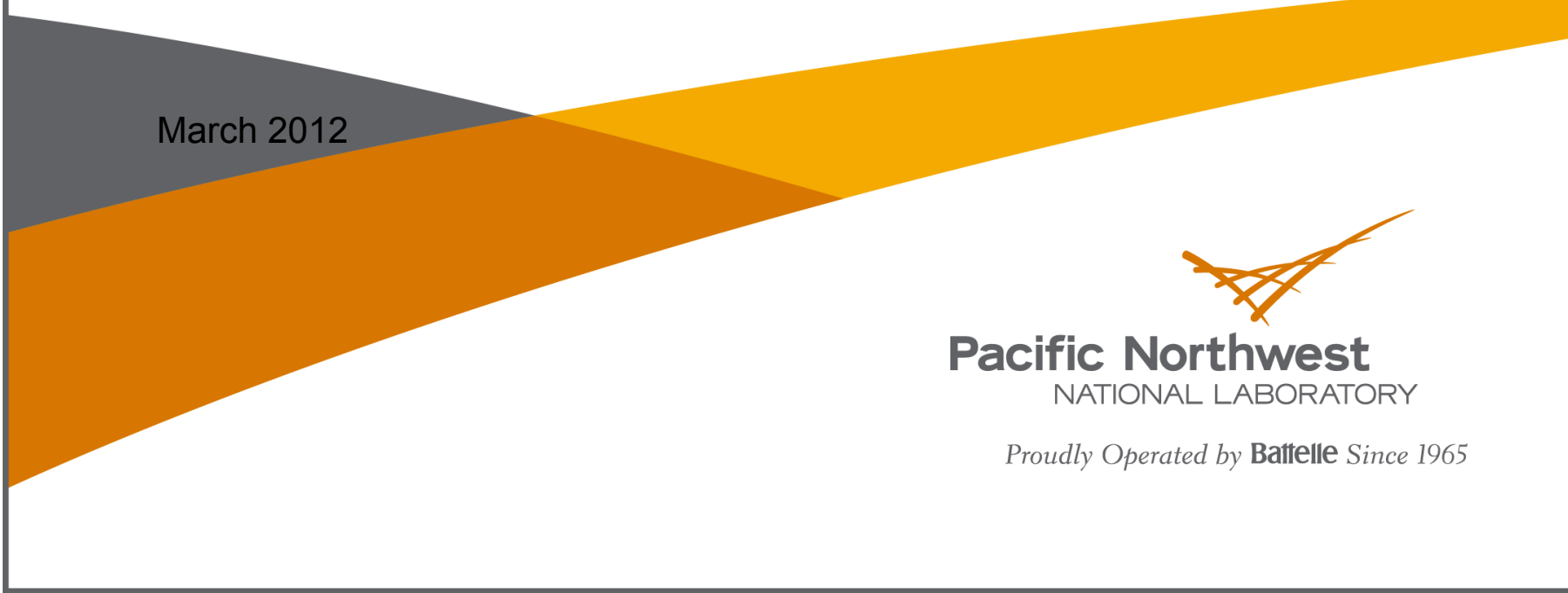




\title{
DISCLAIMER
}

This report was prepared as an account of work sponsored by an agency of the United States Government. Neither the United States Government nor any agency thereof, nor Battelle Memorial Institute, nor any of their employees, makes any warranty, express or implied, or assumes any legal liability or responsibility for the accuracy, completeness, or usefulness of any information, apparatus, product, or process disclosed, or represents that its use would not infringe privately owned rights. Reference herein to any specific commercial product, process, or service by trade name, trademark, manufacturer, or otherwise does not necessarily constitute or imply its endorsement, recommendation, or favoring by the United States Government or any agency thereof, or Battelle Memorial Institute. The views and opinions of authors expressed herein do not necessarily state or reflect those of the United States Government or any agency thereof.

\author{
PACIFIC NORTHWEST NATIONAL LABORATORY \\ operated by \\ BATTELLE \\ for the \\ UNITED STATES DEPARTMENT OF ENERGY \\ under Contract DE-AC05-76RL01830
}

This document was printed on recycled paper. 


\section{Tailored Materials for High Efficiency CIDI Engines (CAT)}

Final Report for CRADA

No. PNNL/272 with

Caterpillar, Inc.

GJ Grant

S Jana

March 2012

Prepared for

the U.S. Department of Energy

under Contract DE-AC05-76RL01830

Pacific Northwest National Laboratory

Richland, Washington 99352 



\section{Summary}

The overall goal of the project, Tailored Materials for High Efficiency Compression Ignition Direct Injection (CIDI) Engines, is to enable the implementation of new combustion strategies, such as homogeneous charge compression ignition (HCCI), that have the potential to significantly increase the energy efficiency of current diesel engines and decrease fuel consumption and environmental emissions. These strategies, however, are increasing the demands on conventional engine materials, either from increases in peak cylinder pressure (PCP) or from increases in the temperature of operation. The specific objective of this project is to investigate the application of a new material processing technology, friction stir processing (FSP), to improve the thermal and mechanical properties of engine components. The concept is to modify the surfaces of conventional, low-cost engine materials. The project focused primarily on FSP in aluminum materials that are compositional analogs to the typical piston and head alloys seen in small- to mid-sized CIDI engines. Investigations have been primarily of two types over the duration of this project: (1) FSP of a cast hypoeutectic Al-Si-Mg (A356/357) alloy with no introduction of any new components, and (2) FSP of Al-Cu-Ni alloys (Alloy 339) by physically stirring-in various quantities of carbon nanotubes/nanofibers or carbon fibers. Experimental work to date on aluminum systems has shown significant increases in fatigue lifetime and stress-level performance in aluminumsilicon alloys using friction processing alone, but work to demonstrate the addition of carbon nanotubes and fibers into aluminum substrates has shown mixed results due primarily to the difficulty in achieving porosity-free, homogeneous distributions of the particulate.

A limited effort to understand the effects of FSP on steel materials was also undertaken during the course of this project. Processed regions were created in high-strength, low-alloyed steels up to 0.5 in. deep that showed significant grain refinement and homogeneous microstructures favorable to increased fracture toughness and fatigue performance.

The final tasks of the project demonstrated that the FSP concept can be applied to a relevant part geometry by fabricating diesel piston crowns with FSP regions applied selectively to the edge of the bowl rim. This area of the piston typically suffers from conditions at high PCP that cause severe thermal fatigue issues. It is expected that, given the data from coupon testing, the durability of pistons modified by FSP will allow much higher fatigue lifetime and potentially also greater resistance to elevated stress-level effects on fatigue. 



\section{Acknowledgments}

We would like to specifically acknowledge the help and guidance from Caterpillar personnel Brad Beardsley, Mark Veliz, and Nate Phillips. We also would like to acknowledge Leo Fifield and Nancy Hess for their respective work on nanotube channel fabrication and Raman spectroscopy. The project was funded through the U.S. Department of Energy's Energy Efficiency and Renewable Energy Vehicle Technologies Propulsion Materials Program (Jerry Gibbs, Manager). 



\section{Acronyms and Abbreviations}

AGG

APR

CIDI

$\mathrm{C}_{\mathrm{p}}$

CRADA

CTE

FSP

FY

GRPH

HCCI

PAN

PCP

RPM

S-N

SEM

SP abnormal grain growth

advance per revolution

compression ignition direct injection

specific heat, heat capacity

Cooperative Research and Development Agreement

coefficient of thermal expansion

friction stir processing

fiscal year

graphite

homogeneous charge compression ignition

polyacrylonitrile

peak cylinder pressure

revolutions per minute

stress versus number of cycles to failure

scanning electron microscope

specific power 



\section{Contents}

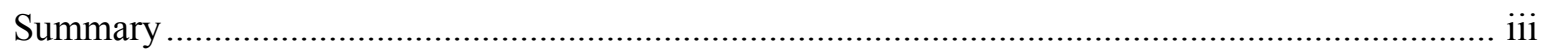

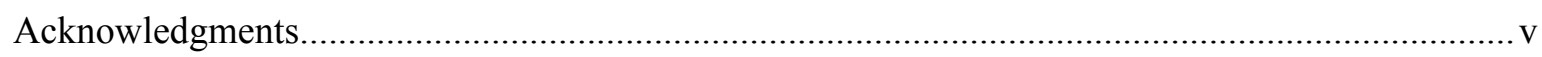

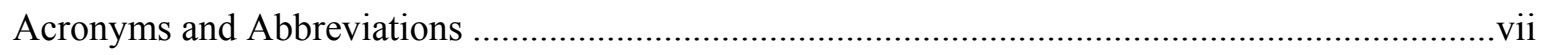

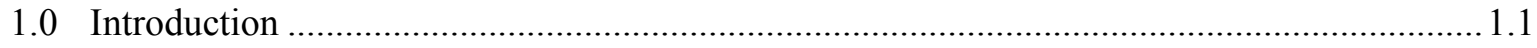

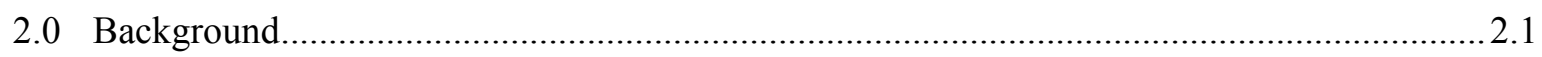

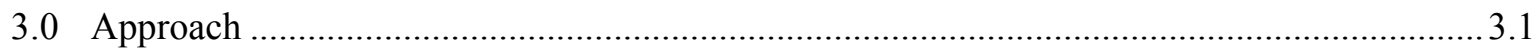

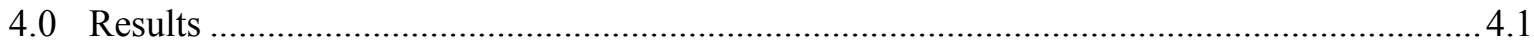

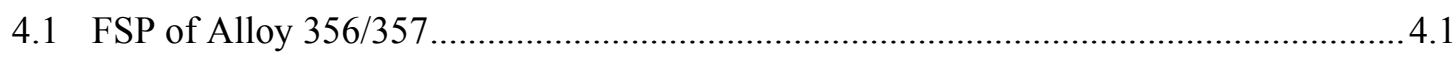

4.2 Abnormal Grain Growth in FSP Aluminum Alloys...................................................... 4.4

4.3 FSP — “Stirring-in” Carbon Nanotubes and Nanofibers............................................... 4.6

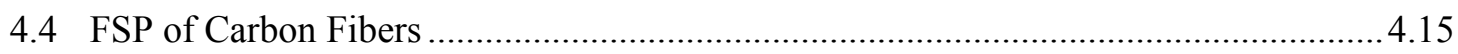

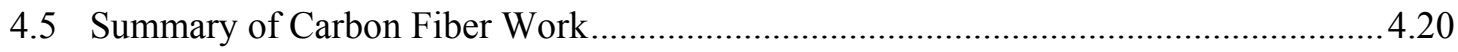

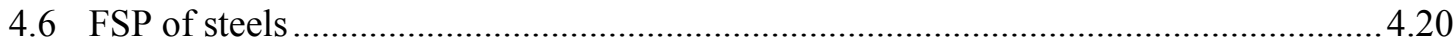

5.0 Part Prototyping —Piston Bowl Rim FSP ........................................................................ 5.1

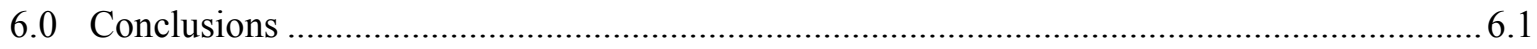

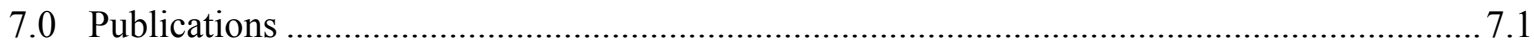

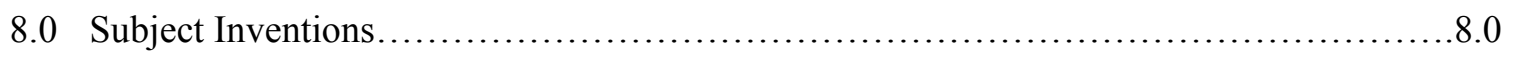




\section{Figures}

2.1. Increase in SP and PCP for Typical Heavy-Duty Diesel Engines over the Last 38 Years .....2.1

2.2. a) Piston in Bore; b) Cracks on Inside Edges of Bowl Rim; c) Bowl Rim Failure..................2.2

2.3. FSP Illustration (left) and Typical Friction Stir Tools (right) .............................................. 2.3

2.4. Micrograph of the Edge of a Stirred Zone Showing Particle Refinement in the Processed

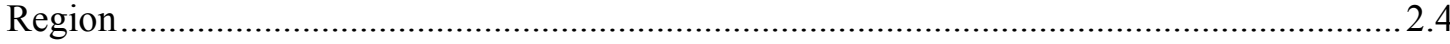

2.5. Ceramic Particulate can be Stirred into the Surface to Produce Functionally Graded Surfaces

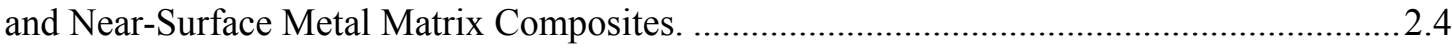

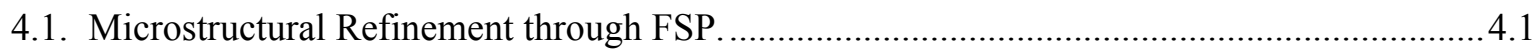

4.2. S-N Curve for (a) Tensile Loading at $\mathrm{R}=0.1$; (b) $\mathrm{S}-\mathrm{N}$ Curve for Bending at $\mathrm{R}=-1$; (c) Basquin Plot for A357 Alloy at $\mathrm{R}=0$.

4.3. (a) Average Crack Growth Rate as a Function of Crack Length in FSP Condition; (b) Comparison of Crack Growth Rates in Cast vs. FSP Condition.

4.4. (a) Fine Fatigue Striations in FSP Condition; (b) Coarse Striations in As-Cast Condition .....4.4

4.5. (a) Single Pass; (b) Multiple Pass, 0\% Nugget Overlap; (c) Multiple Pass Type I, 50\% Nugget Overlap; (d) Multiple Pass Type II, 50\% Nugget Overlap; (e) Multiple Pass, 100\% Nugget Overlap.

4.6. Cross-Section Macrograph of Multi-Pass Run with Minor Nugget Overlap. AGG is noted throughout the cross section (arrows). Run parameters are $1500 \mathrm{rpm}$ and $2.33 \mathrm{~mm} / \mathrm{sec} \ldots \ldots \ldots . .4 .5$

4.7. Cross-Section Macrograph of Multi-Pass Run Involving 100\% Nugget Overlap...................4.6

4.8. (a) Fully Consolidated FSP Region in Cast 339 Alloy; (b) Micrograph of Edge of Stirred Zone Showing Particle Refinement in Processed Region........................................................ 4.6

4.9. Carbon Nanotube/Aluminum Powder Mixtures were Loaded into Aluminum Tubes, Cut,

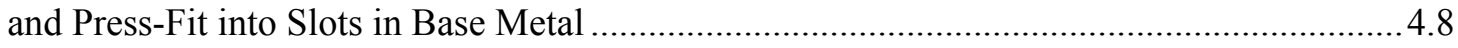

4.10. Nanotube and Nanofiber FSP Trials on 339 Plate ............................................................ 4.8

4.11. Nanotubes are Packed into Grooves and a Cap Plug is Installed Prior to FSP ......................4.9

4.12.Illustration of Variables around Multipass FSP ................................................................. 4.10

4.13.(a) Overlap Pattern that Consumes Retreating Side of Nugget and (b) Overlap Pattern that Consumes Advancing Side of Nugget ............................................................................. 4.10

4.15.Higher Magnification View of Figure 4.14 Showing Relatively Wide Banding and Segmenting of Nanotube-Rich Areas .....

4.16.Processed Region at the Lowest APR ........................................................................ 4.11

4.17.Higher Magnification View of Figure 4.16 Showing Fine Banding.................................... 4.12

4.18. Characteristic Spectrum for Carbon Nanotubes in Raman Spectroscopy ............................4.12

4.19.High APR Case - Nanotubes Occur as Agglomerates and Line Edges of Voids.................4.13

4.20.Low APR Case-Agglomerates are not as Pronounced......................................................4.14

4.21.Low APR Case - Agglomerates are not as Pronounced....................................................4.15

4.22. Schematic Drawing of the Technique Used for Reinforcing Aluminum Plate with Carbon

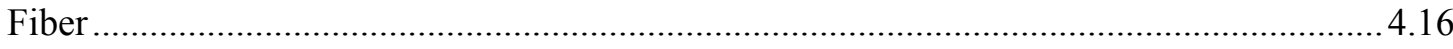

4.23. Cross-Section Images of the Process Region................................................................ 4.16 
4.24.Cross-Section Images from the PAN-Filled Process Zone;

4.25.Higher Magnification Images from the Processed Zone Show the Fragmentation of the Individual Fibers, and Uniform Distribution Inside the Al Matrix

4.26.(a): SEM Image Showing Fragmentation of Carbon Fibers Inside the Process Zone;

(b): Aluminum-Carbon Fiber Interface Without Aluminum-Carbide Reaction Zone.

4.27.Hardness Profile Map of the PAN-Filled Reprocessed Section

4.28.(a) Hardness Profile Plot for T6-Treated PAN-Filled Section; (b) Macrograph of the Profiled Section.

4.29.(a) Hardness Profile of T6-Treated GRPH-Filled Section; (b) Macrograph of the Profiled Section

4.30.(a) Thermal Diffusivity vs. Temperature; (b) Thermal Conductivity vs. Temperature .........4.20

4.31. Macrograph of an FSP-processed Region in Low-Carbon Steel .........................................4.21

5.1. FSP Applied to Cast Piston Blank.

5.2. (a) Circular Process Region Created by "Welding" in a Counterclockwise Direction, then Turning to Center and Exiting Where the Piston Bowl Will be Located; (b) the Arrow Points Toward a Faint Line Demarking the Edge of the FSP Processed Zone on the Bowl Rim after Machining. 


\section{Tables}

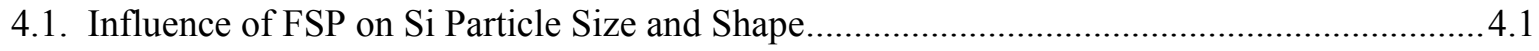

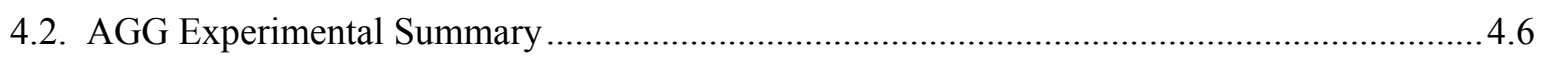

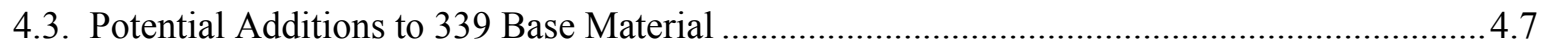

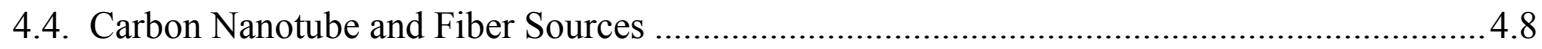

4.5. Bulk Density $(\mathrm{g} / \mathrm{cc})$ of Samples in This Study ..................................................................... 4.19 


\subsection{Introduction}

The overall goal of this project is to enable the implementation of new combustion strategies, such as homogeneous charge compression ignition ( $\mathrm{HCCI}$ ), that have the potential to significantly increase the energy efficiency of current diesel engines and decrease fuel consumption and environmental emissions. These strategies, however, are increasing demands on conventional engine materials, either from increases in peak cylinder pressure (PCP) or from increases in the temperature of operation. The specific objective of this project is to investigate the application of a new material processing technology, friction stir processing (FSP), to improve the thermal and mechanical properties of engine components. The concept is to modify the surface of conventional, low-cost engine materials. The approach is to produce components with functionally graded surfaces that are optimized for thermal properties and better in-service performance without suffering the cost penalty of using exotic or expensive materials.

Low-cost, higher-performance materials will allow new combustion strategies to be implemented that can improve energy efficiency. This project is a Cooperative Research and Development Agreement (CRADA) in partnership with Caterpillar, Inc. 



\subsection{Background}

Almost since the inception of internal combustion engines, there has been a steady rise in specific power (SP) output, or the power per liter of engine displacement. SP is correlated with efficiency and is the combined effect of better optimization of combustion, fuels, engine materials and design, reduction in parasitic losses, and improved heat management. The red line in Figure 2.1 shows that, from 1970 to 2001, there was a steady increase in SP. After 2001, the SP levels dropped due to emission and aftertreatment devices and controls mandated by federal legislation (primarily increased exhaust-gas recirculation rates and particulate filters). The drop in SP from 2001 to about 2003 would have been even greater were it not for significant advances in engine management and computer control, higher injection pressures, etc., made during this period to compensate for the power losses. However, around 2003, a different restriction on the optimization of the combustion process was beginning to force diminishing returns. The restriction is illustrated in Figure 2.1 as the plot of the PCP (blue). As the peak pressure increases, more work can be done by the piston as it is forced downward in the bore, resulting in a higher SP.

Since 2003, PCP has leveled at around 190-200 bar, because above this level, conventional engine materials in pistons, cylinder liners, and cylinder heads will be beyond strength and fatigue limits. ${ }^{1}$ To increase efficiency further, either unconventional, expensive materials (i.e., nickel alloys, titanium, compacted graphite iron, nodular iron, or micro-alloyed steels) must be used or conventional materials must be modified in a way that increases their durability. New energy-efficient combustion strategies, especially HCCI, will increase PCP potentially above 220 bar. Accordingly, materials must be improved to enable this process.

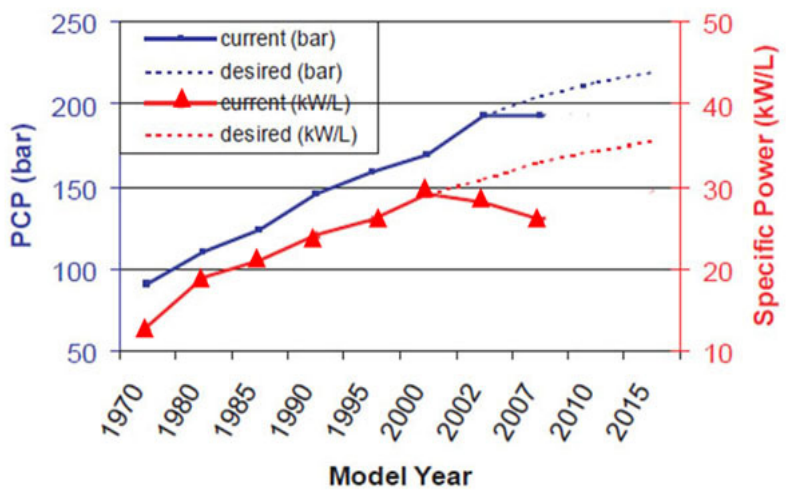

Figure 2.1. Increase in SP and PCP for Typical Heavy-Duty Diesel Engines over the Last 38 Years

(Figure modified from the Southwest Research Institute website at www.swri.org.)

\footnotetext{
${ }^{1}$ Figure 2.1 represents data primarily from medium-duty to heavy-duty diesel engines. Production automotive diesel engines (light-duty, high-speed) now achieve SP levels up to $75 \mathrm{~kW} / \mathrm{L}$ in turbocharged and intercooled configurations.
} 
One of the major challenges for conventional materials under increasing peak-pressure environments is resistance to thermal fatigue failure. Pistons and cylinder heads are particularly vulnerable to this failure mode because of the cyclic nature of the loading and temperature changes in the combustion chamber. Figure 2.1 shows failures of pistons in the bowl rim area when subjected to high PCP over time.
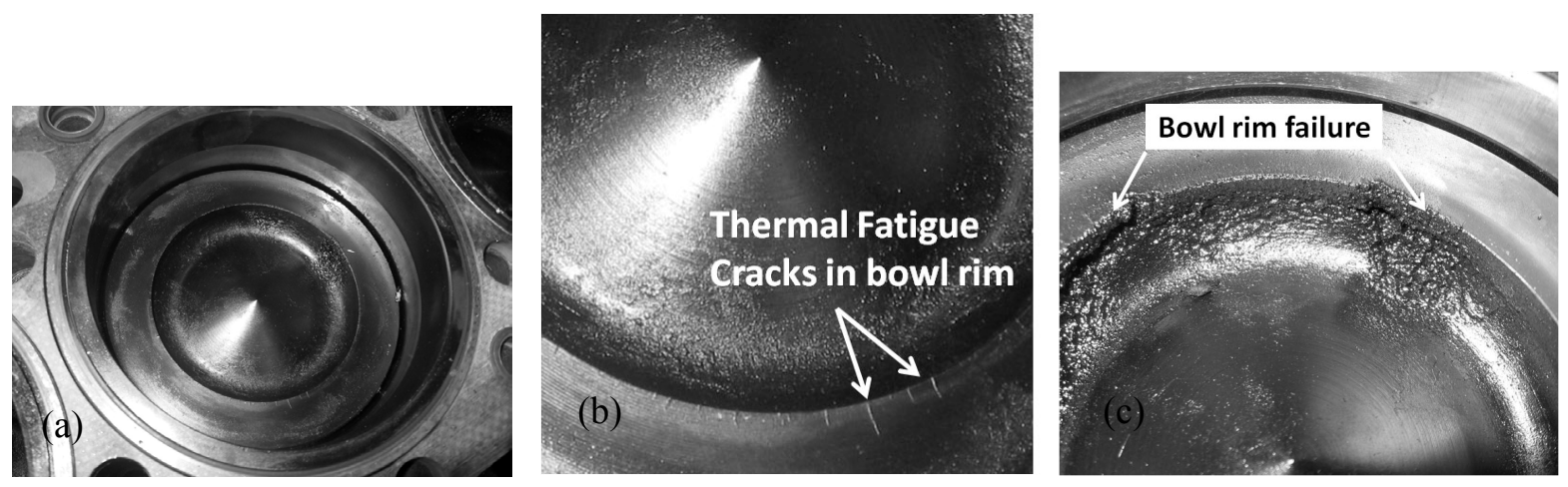

Figure 2.2. a) Piston in Bore; b) Cracks on Inside Edges of Bowl Rim; c) Bowl Rim Failure

Rather than substitute a potentially high-cost, high-temperature, monolithic material, one low-cost strategy to enable higher PCP involves using techniques to improve the thermal fatigue performance of current materials. In the case of thermal fatigue in the bowl rim area, the technique need only be applied to the narrow area around the bowl rim itself because failures of this area drive the overall material selection. FSP is a new technology that can be used to create engineered regions on selective areas of a part. In recent years, Pacific Northwest National Laboratory (PNNL) has developed techniques and tools that allow FSP to be accomplished in steel, cast iron, and aluminum.

FSP is an outgrowth of friction stir welding, which was invented in 1991 by TWI, Ltd. (Figure 2.3). It has been recognized that the same techniques and processes used to make a friction-stir weld could be used to process a material for enhanced properties. The process can be selectively applied to the surface of a material; it alters the microstructure by the severe plastic deformation that occurs in the processed zone. FSP can create a robust and graded structure with fundamentally different properties from the underlying surface, and it has been shown to produce surface regions with improved fatigue life, ductility, and strength. 

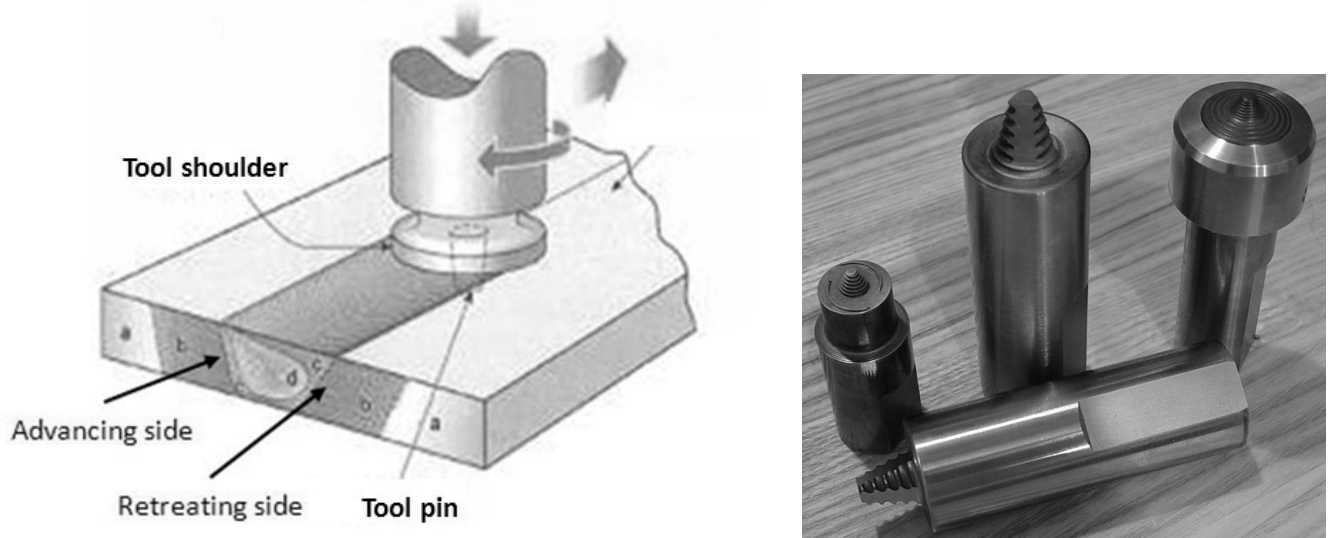

Figure 2.3. FSP Illustration (left) and Typical Friction Stir Tools (right)

FSP produces a surface modified region that is different from a coating. Commonly, surface treatments designed to enhance wear or thermal performance include various coating methods or fusion-welded hard facings. Most of these processes are liquid state and often involve detrimental temperature effects on the base material. Heat-affected zones in the base metal and various deleterious high-temperature reactions can create a coated part with less-than-desirable properties.

Also, traditional thin coatings can suffer from issues involving the nature of the interface between the coating and the base material (spalling, debonding, and cracking on the interface), especially under highstress, gouging wear conditions or under cycling thermal conditions where mismatch of the coefficients of thermal expansion (CTE) is an issue. Also, failure of a coating under high loading conditions can occur when the substrate below a thin, hard coating fails by plastic deformation. Regions treated with FSP can be significantly more robust than traditional coatings for two reasons: 1) FSP produces a modified region that transitions to the base material without a sharp interface, as can be seen in Figure 2.4, and 2) the modified region is generally thicker, and the transition region wider, than traditional coating because the depth of the plasticized region is related to the tool geometry, specifically the depth and size of the pin. 


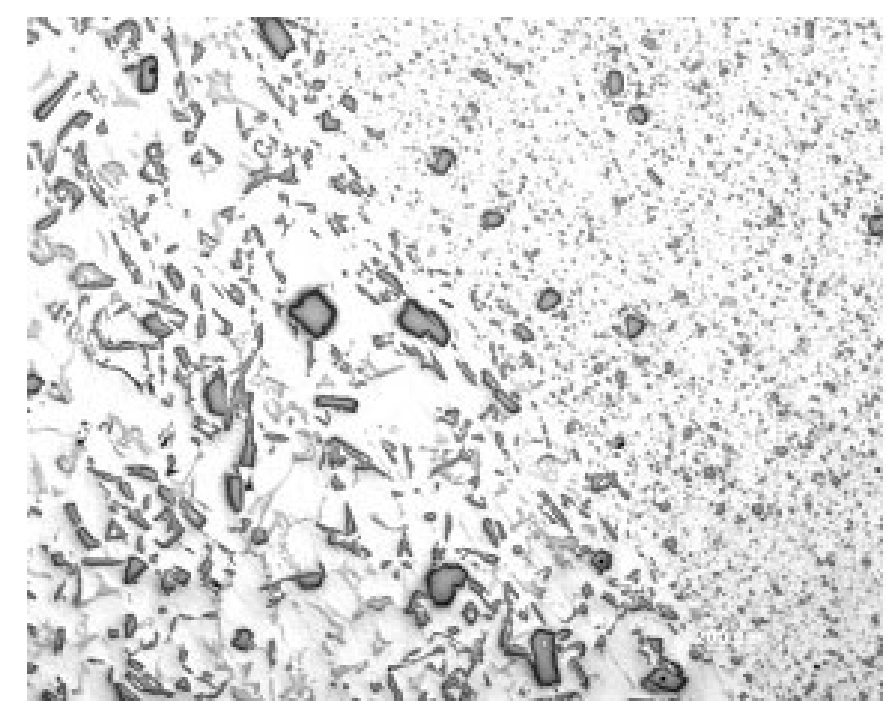

Figure 2.4. Micrograph of the Edge of a Stirred Zone Showing Particle Refinement in the Processed Region (FSP can close porosity in castings and decrease both size and aspect ratio of particles, thereby producing better fatigue performance.)

It also is possible to use FSP to "stir" insoluble particles from the surface into the substrate to depths limited only by the FSP tool geometry, e.g., Figure 2.5. This engineered metal matrix composite layer can create unique surface properties, including increased hardness, wear resistance, and thermal characteristics. To date, the addition of up to $20 \%$ ceramic to aluminum has been demonstrated and approximately $10 \%$ addition to steel has been achieved.

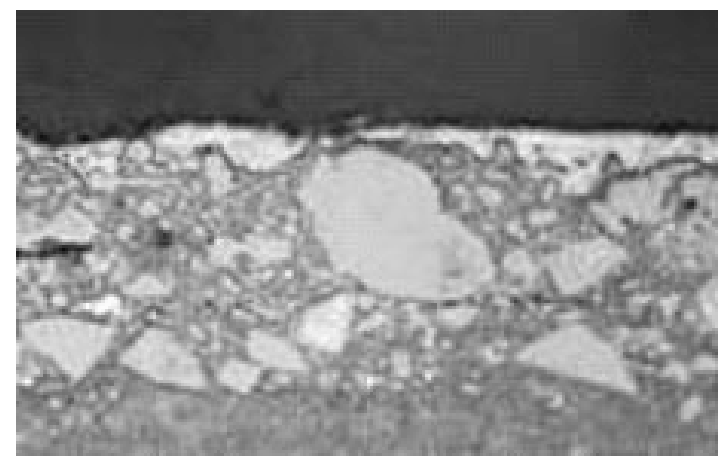

Figure 2.5. Ceramic Particulate can be Stirred into the Surface to Produce Functionally Graded Surfaces and Near-Surface Metal Matrix Composites.

FSP can be used to alter the original microstructure, create surface composites and new alloys, and has the potential to produce selective areas of improved material performance. This project investigated several opportunities for FSP to improve engine materials to enable increases in engine efficiency. 


\subsection{Approach}

This project experimentally developed the FSP processes and technologies required to engineer the surface of propulsion materials for improved properties. The application focus was to tailor the mechanical properties and thermal conductivity of engine materials, both ferrous and nonferrous materials, by using FSP techniques. This microstructural modification is expected to lead to a set of materials with enhanced surface properties that can handle increased combustion pressure and exhaust temperatures, resulting in improved engine efficiency.

The project scope involves developing the FSP manufacturing parameters, and selecting and evaluating proper tool materials and techniques to produce defect-free FSP regions. Coupon-level testing and evaluation of the thermal and mechanical properties was conducted. These efforts focused on specific performance targets identified by project partners. For some FSP investigations, the performance metrics were met, and additional work was done developing and demonstrating the appropriate method to apply this process to two-dimensional and three-dimensional geometries. If successfully commercialized, this class of engineered materials can significantly impact the efficiency and durability of CIDI and potentially address some of the technical barriers to implementing HCCI engines. 



\subsection{Results}

The project focused primarily on FSP in aluminum materials that are compositional analogs to the typical piston and head alloys seen in small- to mid-sized CIDI engines. Investigations have been primarily of two types over the duration of this project: (1) FSP of cast hypoeutectic Al-Si-Mg (A356/357) alloy with no introduction of any new components, and (2) FSP of Al-Cu-Ni alloys (Alloy 339 ) by physically stirring-in various quantities of carbon nanotubes/nanofibers or carbon fibers.

\subsection{FSP of Alloy 356/357}

FSP significantly refines microstructure, closes casting porosity, and reduces the aspect ratio of the $\mathrm{Si}$ particles in cast Al-Si-Mg alloys. Table 4.1 summarizes details of Si particle size and shape before and after FSP, demonstrating that FSP led to more than 50\% reduction in particle size and aspect ratio in terms of both mean and maximum values. Also notable are the lower standard deviation values in both particle size and aspect ratio associated with the FSP microstructure. Further, particle size and distribution were similar throughout the processed cross-section. Figure 4.1 is a graphical example of the microstructural refinement possible through FSP. Complete breakdown of the cast dendritic structure, together with a homogeneous distribution of Si particles is apparent.

Table 4.1. Influence of FSP on Si Particle Size and Shape

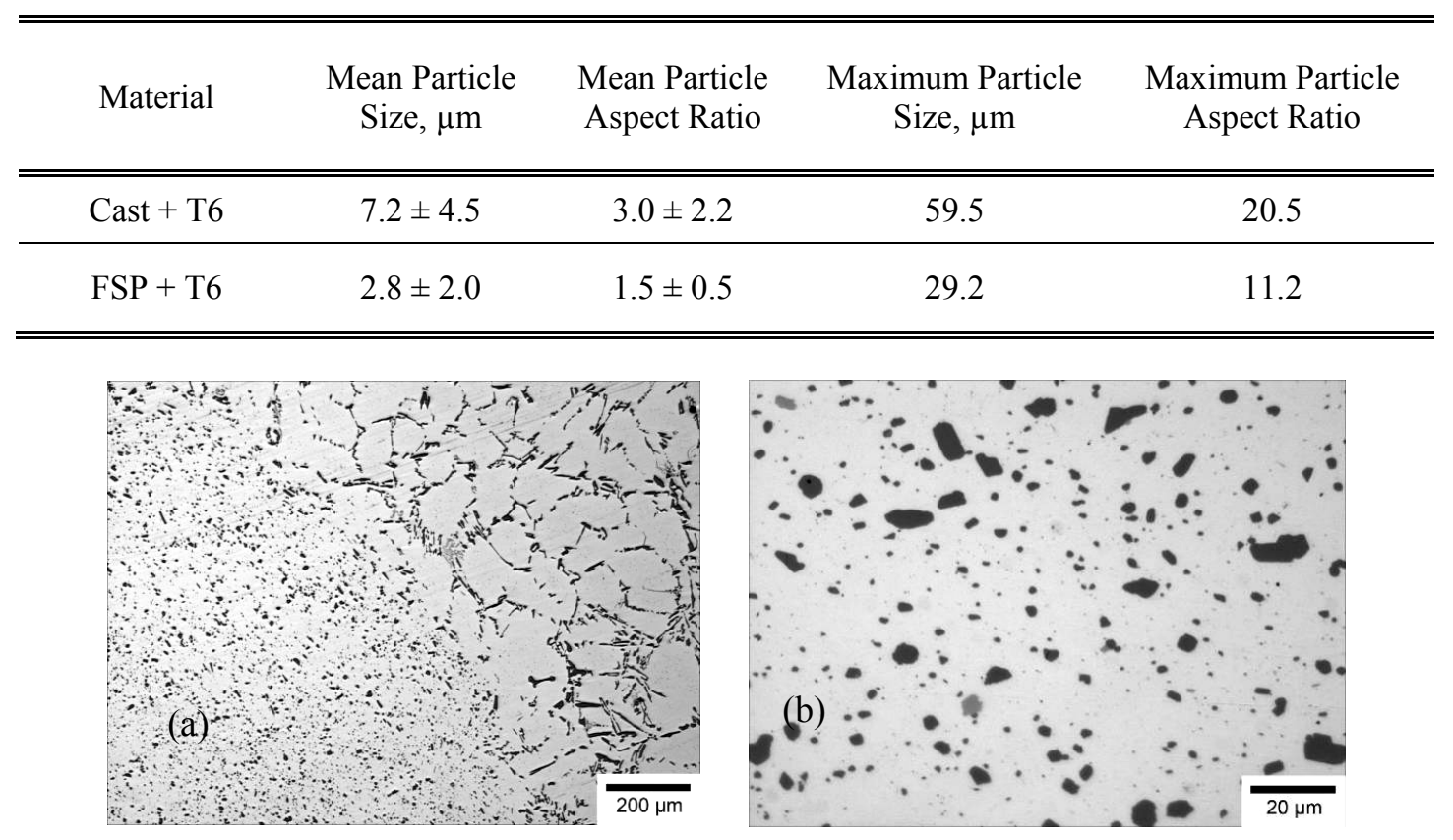

Figure 4.1. Microstructural Refinement through FSP. (a) Complete Breakdown of the Cast Structure inside the Processed Zone; (b) Magnitude of Particle Refinement Possible through FSP

The microstructural modification, achieved through FSP, produces a dramatic improvement in fatigue performance. Figure 4.2 shows the curves for stress versus number of cycles to failure (S-N) for both tensile and bending fatigue performance comparing the as-cast to the friction stir processed material. FSP resulted in a 90\% improvement in the fatigue limit in a sand cast A356 alloy. For an investment cast 
A357 alloy, with a porosity volume fraction of only $\sim 0.2 \%$, close to an order of magnitude enhancement in fatigue life could be observed because of FSP. Further, a 15 times improvement in fatigue life was noted in the friction stir processed A357 alloy when the stress ratio, $\mathrm{R}$, was changed from -1 to 0 . This means that an additional benefit in fatigue performance can be obtained by intelligent design and proper placement of the friction stir processed zone in any engineering structure.

The microstructure of the tested fatigue samples was examined in detail to help explain the improved performance. Post-failure analysis of the fatigue sample surface revealed that cracks initiated at porosity corners in the cast sample, and moved through both aluminum dendrites as well as through inter-dendritic regions rich in Si particles. The crack preferred to move in a straight line fashion inside the $\alpha$-Al dendrites.
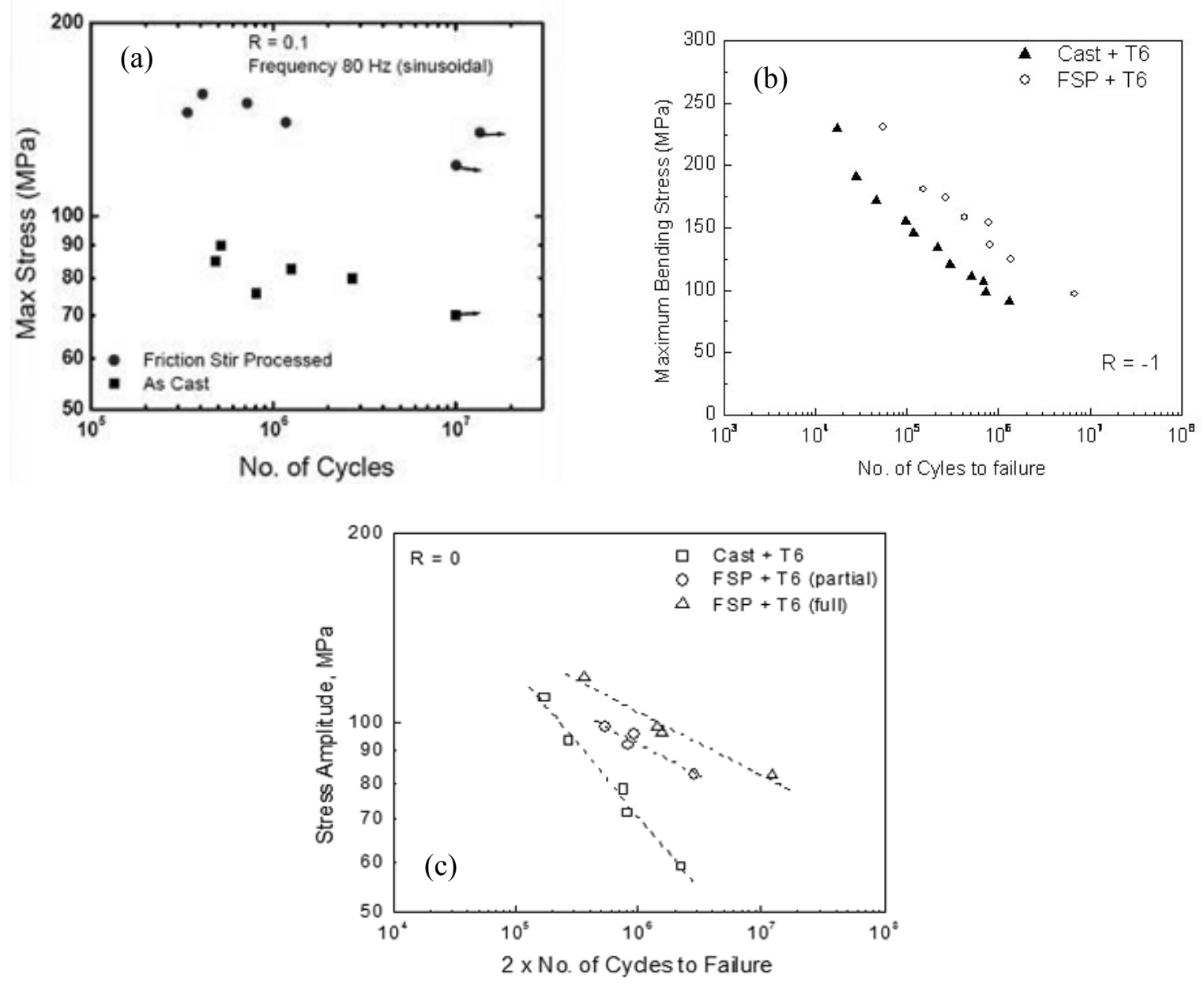

Figure 4.2. $\mathrm{S}-\mathrm{N}$ Curve for (a) Tensile Loading at $\mathrm{R}=0.1$ (Showing As-Cast 356 versus FSP-Processed 356); (b) S-N Curve for Bending at $\mathrm{R}=-1$ (Showing As-Cast 357 versus FSP-Processed 357); (c) Basquin Plot for A357 Alloy at $\mathrm{R}=0$

When a crack encountered Si particles in inter-dendritic regions, the crack path became tortuous. Both particle/matrix decohesion and particle fractures were noted as the crack interacted with Si particles along its length. In the friction stir processed condition, fatigue crack initiation was noted at larger $\mathrm{Si}$ particle corners. FSP led to a uniform distribution of refined Si particles inside the process zone, which 
increased crack meandering, and increased crack branching. Additionally, through the use of optical microscopy, it was possible to determine the average crack growth rate $d a / d N$, i.e., the crack extension in each fatigue cycle in both cast and FSP conditions. Further, $d a / d N$ could be linked to stress intensity factor range, $\Delta K$, by the well-known Paris' law:

$$
\frac{d a}{d N}=C(\Delta K)^{m}=C(Y \Delta \sigma \sqrt{\pi a})^{m}=C Y^{m}(\Delta \sigma)^{m} \pi^{m / 2}(\sqrt{a})^{m}
$$

where $d a / d N$ is crack growth rate per load cycle, $\Delta K$ is stress intensity factor range, $C$ and $m$ are material constants, $Y$ is a geometrical factor related to crack shapes, $\sigma$ is the applied stress, $a$ is the crack length. For a constant-amplitude fatigue test, $d a / d N$ should be a function of crack length, $a$, assuming $\mathrm{Y}$ to be a constant. When average crack growth rate, $d a / d N$ was plotted against $\sqrt{ } a$ on a log-log scale, a typical crack growth curve was obtained, as shown in Figure 4.3a. The crack growth rate remains a linear function of $\sqrt{ } a$ between $6 \times 10^{4}$ and $2.4 \times 10^{5}$; therefore, this region corresponds to the Paris regime. Below the Paris regime, there is an oscillatory behavior of crack growth rate, whereas above it, there is a precipitous rise in crack growth rate with increasing $\sqrt{ } a$. The rise in crack growth rate, however, is not as apparent in the upper regime due to a lack of data points. The slope, $m$, in the Paris regime was $\sim 2$. However, the published literature indicates $m$ to be $\sim 4$ for the A356/357 alloy system. Figure $4.3 \mathrm{~b}$ compares the average crack growth rate of the as-cast condition to that of the FSP condition. It is evident that average crack growth rate is close to an order of magnitude higher in the cast $+\mathrm{T} 6$ condition as compared to the FSP+T6 condition. Further, the Paris exponent $m$ is $\sim 4$ in cast+T6 condition; therefore, a higher crack growth rate together with a higher Paris exponent results in the lower fatigue life observed in the cast $+\mathrm{T} 6$ condition. Porosity present in the cast specimen acted as notches, and therefore resulted in a higher crack growth rate and lower fatigue life.
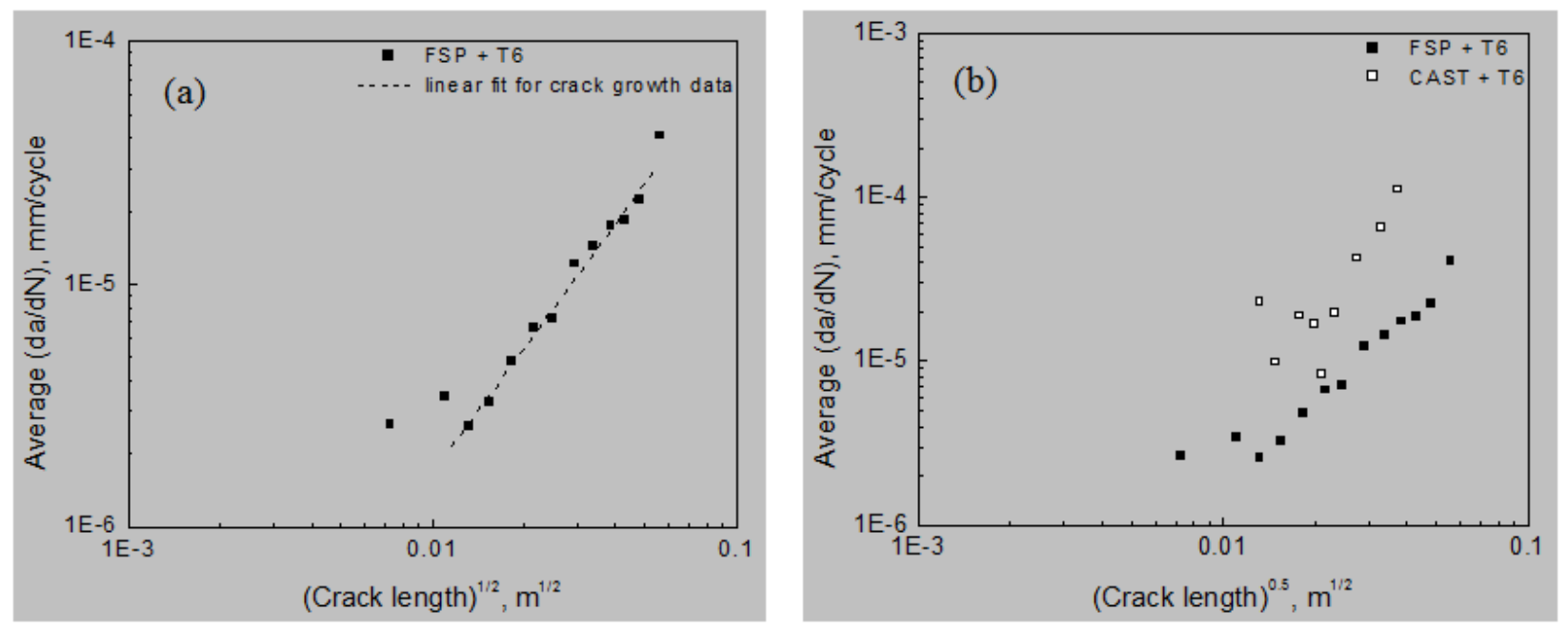

Figure 4.3. (a) Average Crack Growth Rate as a Function of Crack Length in FSP Condition; (b) Comparison of Crack Growth Rates in Cast vs. FSP Condition

In general, stage II or Paris regime fatigue crack growth leads to the formation of fatigue 'striations' in many engineering alloys. For cyclic loads in the Paris regime of fatigue crack advance, it has been found that the spacing between adjacent striations correlates with the experimentally measured average crack growth rate per cycle. Therefore, striation spacing on fracture surfaces is expected to differ between cast and FSP specimens since they show two entirely different crack growth rates. Qualitatively, striation 
spacing should be coarser in the case of a cast alloy, whereas an FSP specimen should show fine striations. Fractographic observations confirmed this trend. Figure 4.4a and Figure 4.4b show certain regions on the fracture surface of an FSP specimen at high magnifications. Characteristic striations with an average spacing of $0.5 \mu \mathrm{m}$ are clearly visible in Figure 4.4a. On the other hand, the cast specimen fracture surface showed the presence of much coarser striations with spacing of $\sim 1 \mu \mathrm{m}$, as shown in Figure $4.4 \mathrm{~b}$.
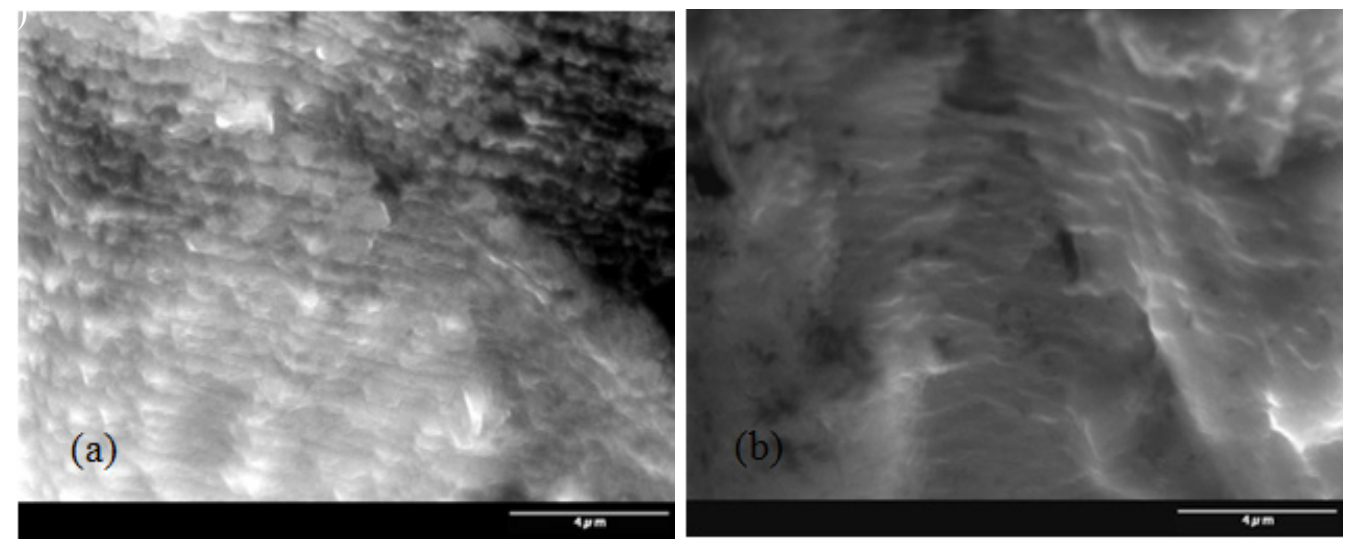

Figure 4.4. (a) Fine Fatigue Striations in FSP Condition; (b) Coarse Striations in As-Cast Condition

\subsection{Abnormal Grain Growth in FSP Aluminum Alloys}

One of the concerns for the application of FSP to aluminum alloys is the possibility, in some alloys and at some processing conditions, of creating a microstructure that is not stable at high temperature. In these cases it has been observed that the fine-grained plastically deformed and recrystallized area will undergo a rapid and exaggerated grain growth event when subjected to elevated temperature. This process is known as abnormal grain growth (AGG). This coarse microstructure can have a negative effect on ductility and toughness (surprisingly, this microstructure can have an unpredictable effect, negative or positive, on other mechanical properties such as fatigue and creep depending on the situation). Therefore, as a part of this research, an investigation of the stability of the refined microstructure at elevated temperatures was also carried out. Tests were carried out to check the stability of the refined grain structure as a function of FSP configuration and process conditions. A number of multiple pass FSP configurations are shown in Figure 4.5 that summarize the experimental effort. A schematic of a multiple pass run with $0 \%$ nugget overlap is illustrated in Figure $4.5 \mathrm{~b}$. " $0 \%$ " nugget overlap means that there is no lateral overlap of the processed or nugget region with each successive run. " $50 \%$ " overlap means that the tool on each consecutive run passes through $50 \%$ of the previously processed nugget area (Figure $4.5 \mathrm{c}$ ). Runs were also made where a second multiple pass run was superimposed on the first, but with the weld direction reversed (Figure 4.5d). And finally runs were made where each successive run was $100 \%$ overlapping the previous (Figure 4.5e). 


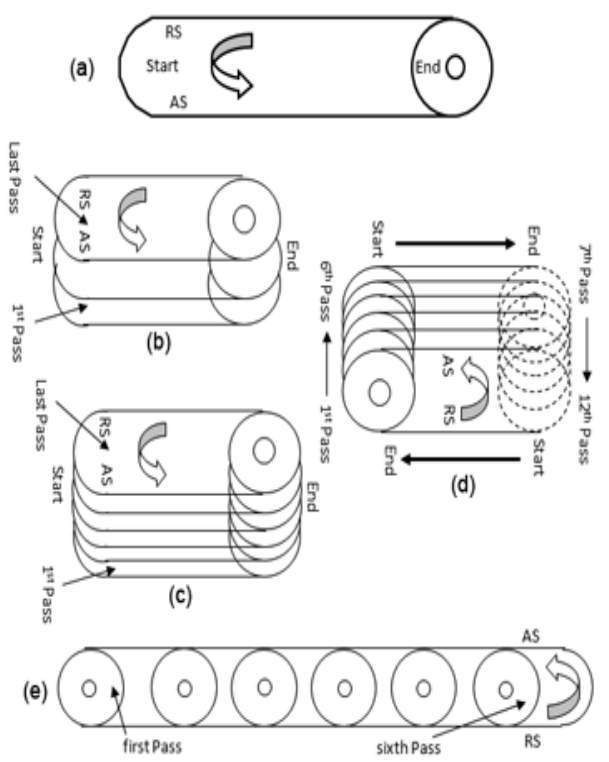

Figure 4.5. (a) Single Pass; (b) Multiple Pass, 0\% Nugget Overlap; (c) Multiple Pass, 50\% Nugget Overlap; (d) Multiple Pass, 50\% Nugget Overlap with a second multiple pass run in the opposite direction superimposed; (e) Multiple Pass, 100\% Nugget Overlap

FSP coupons were made at various processing conditions and following various process overlap sequences. To investigate the stability of the nugget microstructure at high temperature, cross sections of both single and multiple-pass runs were soaked at $540^{\circ} \mathrm{C}$ for 8 hours, and then quenched in water. This heat treatment is similar to the high temperature solution treatment for alloy F357. Heat treated cross sections were then polished to a $1 \mu \mathrm{m}$ finish and chemically etched for further optical metallographic examination. Results indicated that AGG occurs for the single pass and multiple pass with $0 \%$ nugget overlap configurations (Figure 4.6).

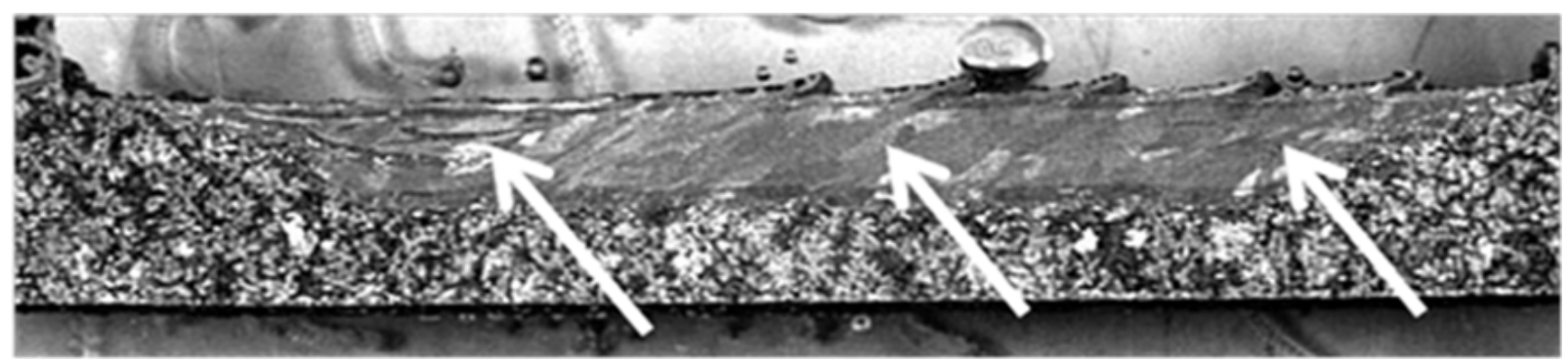

Figure 4.6. Cross-Section Macrograph of Multi-Pass Run with Minor Nugget Overlap. AGG is noted throughout the cross section (arrows). Run parameters are $1500 \mathrm{rpm}$ and $2.33 \mathrm{~mm} / \mathrm{sec}$.

However, multiple-pass runs with 50\% nugget overlap showed resistance to AGG with an increase in the number of passes. In the multiple-pass Type II configuration, the refined grain structure could be completely preserved by carrying out the processing twice, from opposite directions. Further, the multiple-pass run with 100\% nugget overlap conclusively showed the importance of repeated FSP to mitigate the AGG issue. Further, it was found that at any given travel speed, tool rotation rate plays a key role in the AGG event. A higher tool rotation rate acts as a deterrent to AGG. The details of various experimental results are summarized in Table 4.2. A typical example of the multiple pass run with $100 \%$ nugget overlap is shown in Figure 4.7. The increased resistance to AGG with increase in number of 
passes is apparent. It is believed that the multiple processing acts to homogenize the microstructure and the constituents that form precipitates, and this homogenization can prevent AGG.

Table 4.2. AGG Experimental Summary

\begin{tabular}{|l|l|}
\hline \hline \multicolumn{1}{|c|}{ Configuration/ Process Parameter Details } & \multicolumn{1}{c|}{ Comments on AGG (Yes/No) } \\
\hline \hline Single pass & Yes \\
\hline Multiple pass, 0\% nugget overlap & Yes \\
\hline Multiple pass, 50\% nugget overlap, Type I, 2236 RPM & No \\
\hline Multiple pass, 50\% nugget overlap, Type II, 2236 RPM & $\begin{array}{l}\text { No } \\
\text { (Type II is more resistant to AGG) }\end{array}$ \\
\hline Multiple pass, 50\% nugget overlap, Type I, 1500 RPM & Yes \\
\hline Multiple pass, 50\% nugget overlap, Type II, 1500 RPM & Yes \\
\hline Multiple pass, 100\% nugget overlap, 2236 RPM & No \\
\hline \hline
\end{tabular}
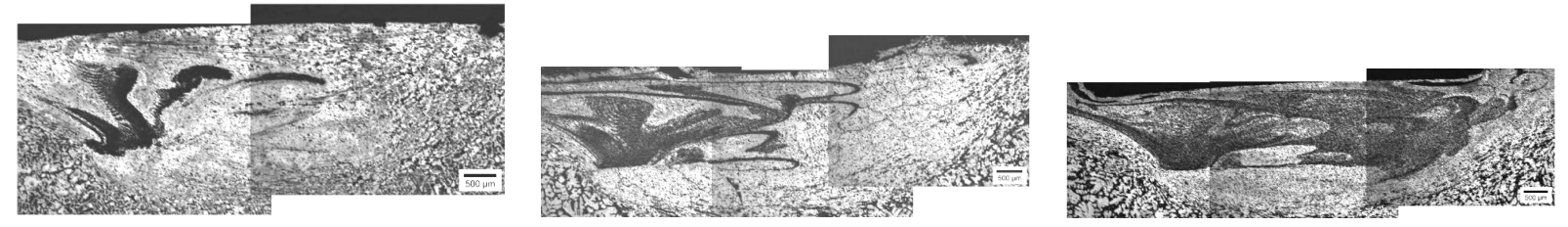

Figure 4.7. Cross-Section Macrograph of Multi-Pass Run Involving 100\% Nugget Overlap: (left) Single pass showing large grains on right side of nugget; (middle) Triple pass showing more finegrained area; (right) Six passes showing almost complete preservation of the fine -grained microstructure after heat treatment

\subsection{FSP_-"Stirring-in" Carbon Nanotubes and Nanofibers}

Another task within this project focused on developing appropriate processing parameters to produce consolidated FSP processed regions in A339 castings (Figure 4.8).
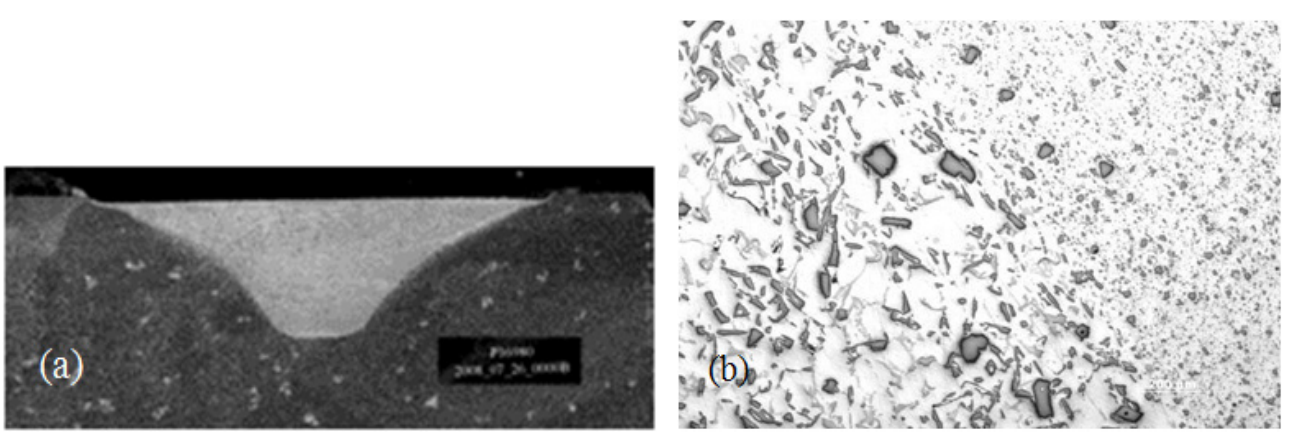

Figure 4.8. (a) Fully Consolidated FSP Region in Cast 339 Alloy. Processed region is approximately 0.25 in. deep. (b) Micrograph of Edge of Stirred Zone Showing Particle Refinement in Processed Region 
During the latter half of the project, efforts focused on improving the fatigue performance of this alloy by FSP. Alloy 339 is close in composition to many diesel piston alloys, and as such is representative of a baseline performance. The primary failure in service is due to fatigue and thermal fatigue at several locations on the piston. We expect this alloy to behave similarly to the $356 / 357$ alloys in its response to FSP, but this task of the project went further to ask whether additional benefits could be realized by not only friction processing the surface, but by using friction processing to both modify the microstructure and add a new component to the surface. Our goal therefore was to use "additive" FSP to improve the mechanical properties that most influence thermal fatigue, those being CTE, conductivity, and to a lesser extent, high temperature strength. The goal is primarily to reduce CTE and increase conductivity. Table 4.3 shows candidate materials that could be stirred into the base metal to potentially selectively modify mechanical properties. Of these, carbon nanotubes and fibers offer the best potential to improve thermal fatigue due to their very low CTE and high conductivity. It should also be noted here that other additions that increase, for example, wear resistance and/or decrease conductivity could be considered to enhance other aspects of part performance such as wear resistance in piston skirts or liners. In this work however, we primarily focused on particle additions to the surface that could affect thermal fatigue.

Table 4.3. Potential Additions to 339 Base Material

\begin{tabular}{|l|l|l|l|}
\hline Material & Modulus & $\mathrm{CTE}$ & Conductivity \\
\hline Aluminum & $80 \mathrm{GPa}$ & $25 \mu \mathrm{m} / \mathrm{m}^{\circ} \mathrm{C}$ & $180 \mathrm{~W} / \mathrm{m}-\mathrm{K}$ \\
\hline $\mathrm{SiC}$ & $410 \mathrm{GPa}$ & $4.4 \mu \mathrm{m} / \mathrm{m}^{\circ} \mathrm{C}$ & $150 \mathrm{~W} / \mathrm{m}-\mathrm{K}$ \\
\hline $\mathrm{Al}_{2} \mathrm{O}_{3}$ & $370 \mathrm{GPa}$ & $8.5 \mu \mathrm{m} / \mathrm{m}^{\circ} \mathrm{C}$ & $13 \mathrm{~W} / \mathrm{m}-\mathrm{K}$ \\
\hline $\begin{array}{l}\text { Carbon } \\
\text { Nanotubes }\end{array}$ & $>600 \mathrm{GPa}$ & $\begin{array}{l}\text { Low or Can } \\
\text { be negative ! }\end{array}$ & $>1000 \mathrm{~W} / \mathrm{m}-\mathrm{K}$ \\
\hline
\end{tabular}

Experimental work consisted of cutting 1/8 in. wide and 3/16 in. wide slots in base plates of aluminum alloy 339 (Figure 4.9). These slots were approximately 1 in. long. Mixtures of aluminum and nanotube powders were then packed in square-section aluminum 3003 tubes and press-fit into the slots. Table 4.4 shows carbon nanotube and nanofiber details. We used nanofibers from Showa Denko Carbon, Inc., and Baytube ${ }^{\circledR}$ multiwall nanotubes from Bayer MaterialScience in this study in 50/50 and 20/80 wt\% ratio mixtures. 


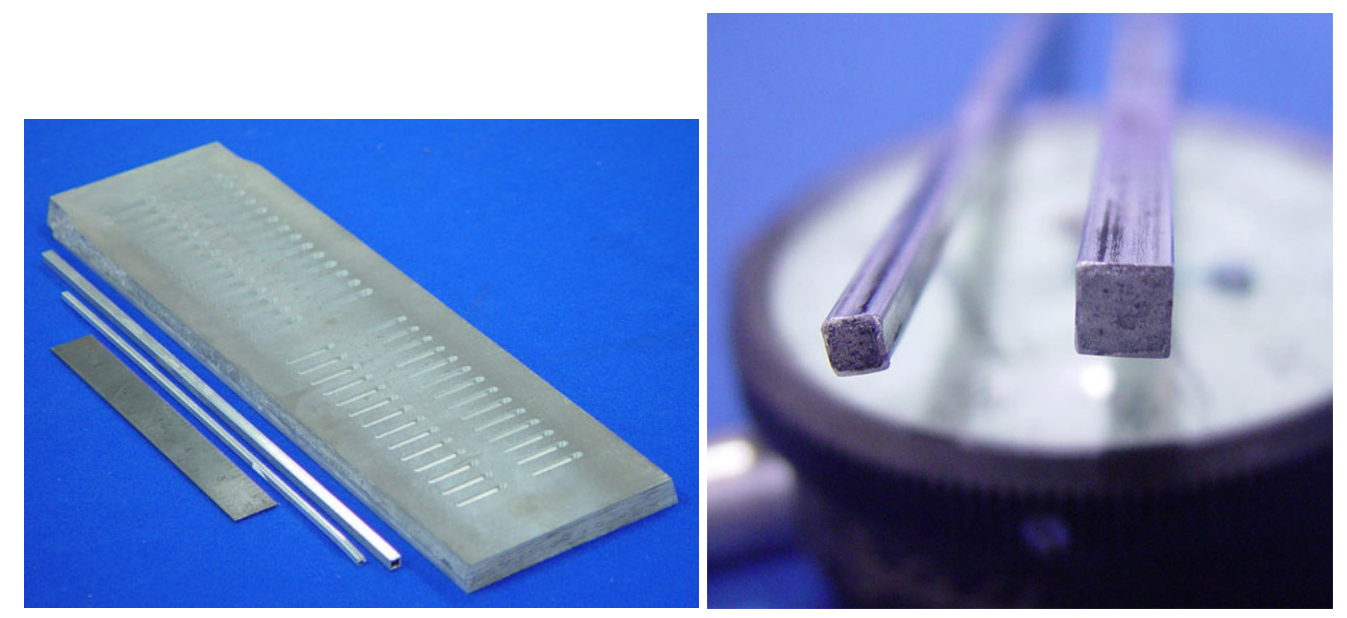

Figure 4.9. Carbon Nanotube/Aluminum Powder Mixtures were Loaded into Aluminum Tubes, Cut, and Press-Fit into Slots in Base Metal

Table 4.4. Carbon Nanotube and Fiber Sources

\begin{tabular}{|l|l|l|c|c|c|}
\hline Product & ID & Source & OD(nm) & Length(um) & BET(m2/g) \\
\hline VGCF & & & & & 13 \\
\hline & VGCF-H & Showa Denko & 150 & 9 & 13 \\
\hline & VGCF-S & Showa Denko & 100 & 10 & \\
\hline & & & & & \\
\hline Pyrograf-III & PR-19-HHT & ASI & $100-200$ & $30-100$ & $15-25$ \\
\hline & PR-24-HHT & ASI & $60-150$ & $30-100$ & \\
\hline & & & & & \\
\hline Baytubes & C 150 P & Bayer & $13-16$ & $1->10$ & \\
\hline & C 150 HP & Bayer & $13-16$ & $1->10$ & \\
\hline
\end{tabular}

Results of the FSP trials indicated that fully consolidated welds with the $1 / 8 \mathrm{in}$. tubes were obtained at a number of different process conditions, and carbon nanotubes were distributed and intimately mixed with the aluminum substrate (Figure 4.10).

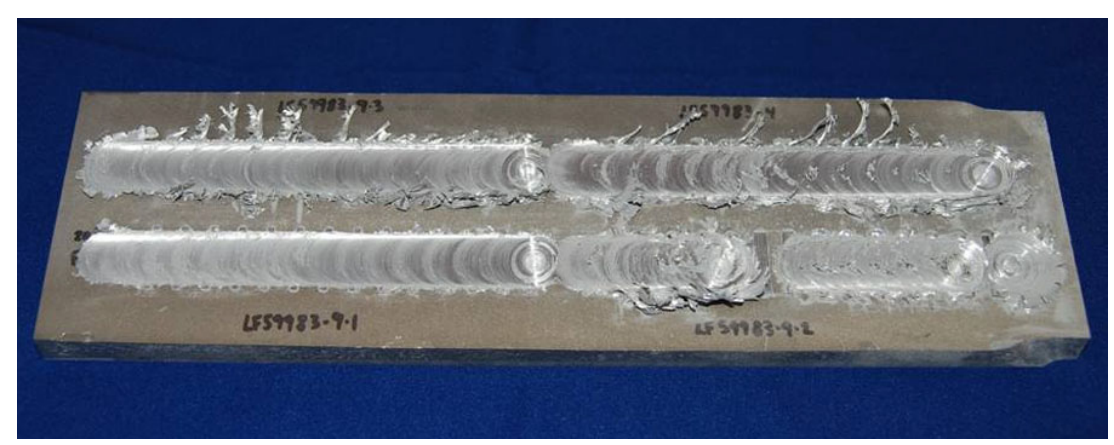

Figure 4.10. Nanotube and Nanofiber FSP Trials on 339 Plate

However, further microstructural analysis on our initial powder addition route showed lack of carbon nanotube mixing along the length of the processed zone. As can be seen in Figure 4.9, carbon-nanotube packed Al tubes were placed transverse to the FSP tool travel direction in our initial attempt. The FSP tool was able to mix the carbon nanotubes into the $\mathrm{Al}$ substrate whenever it came in contact with any of those tubes. However, that process failed to transport carbon nanotubes into the Al matrix between two adjacent tubes. In the next attempts, longitudinal channels were cut into the $\mathrm{Al}$ base plate to obtain more 
uniform powder mixing. Experimental work consisted of cutting 0.25 in. wide longitudinal slots in base plates of aluminum. These slots were approximately 3-6 in. long. Then, $100 \%$ nanotube powders were packed in the slot and covered with an aluminum square-section rod that was press-fit and staked into place (Figure 4.11). The nanotubes used in this study were Bayer Baytubes C150P, a multi-walled nanotube with outer diameter $13-16 \mathrm{~nm}$ and a length from 1 to 10 micron.
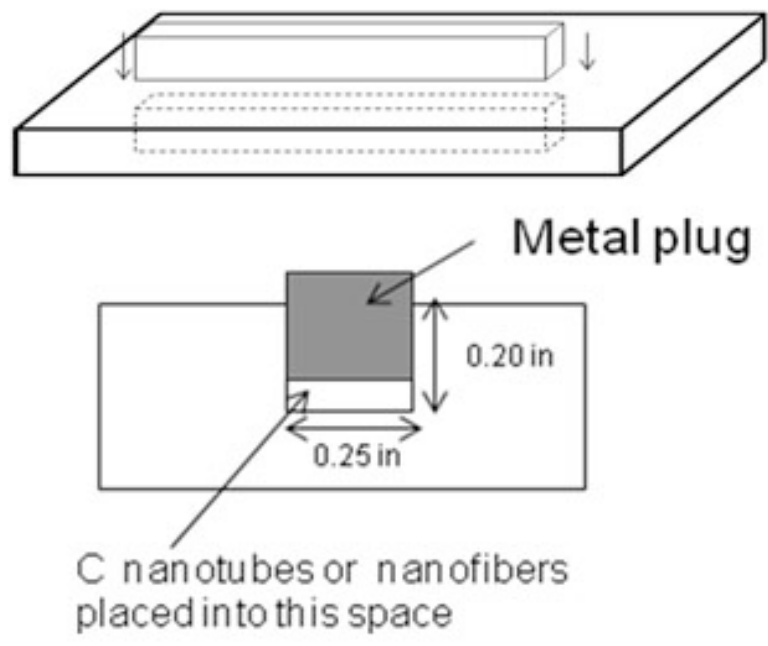

Figure 4.11. Nanotubes are Packed into Grooves and a Cap Plug is Installed Prior to FSP

The metal plug and groove then was processed by multiple overlapping passes of a friction stir tool at a wide range of different parameters and conditions. Variables investigated included rotation rate (RPM), travel speed of the tool, normal load, tool design, number of passes, and order of passes with respect to the advancing and retreating side of the tool. To explain this latter concept, Figure 4.12 shows a multipass overlay FSP run. These overlays can be run so the first pass over the nanotube reservoir is under the advancing or retreating side of the shoulder, and each successive pass can be rastered with either the same or opposite rotation and travel directions. The effect of these differences places the advancing or retreating side of the processed zone in the path of the tool on each run and different flow patterns develop. For example, one result of this work (shown in Figure 4.13b) is that a much better particulate distribution can be obtained if each pass consumes the advancing side of the previous pass. If the retreating side is consumed, there will be a discontinuity in particle loading, seen as the interrupted dark areas in Figure 4.13a. 

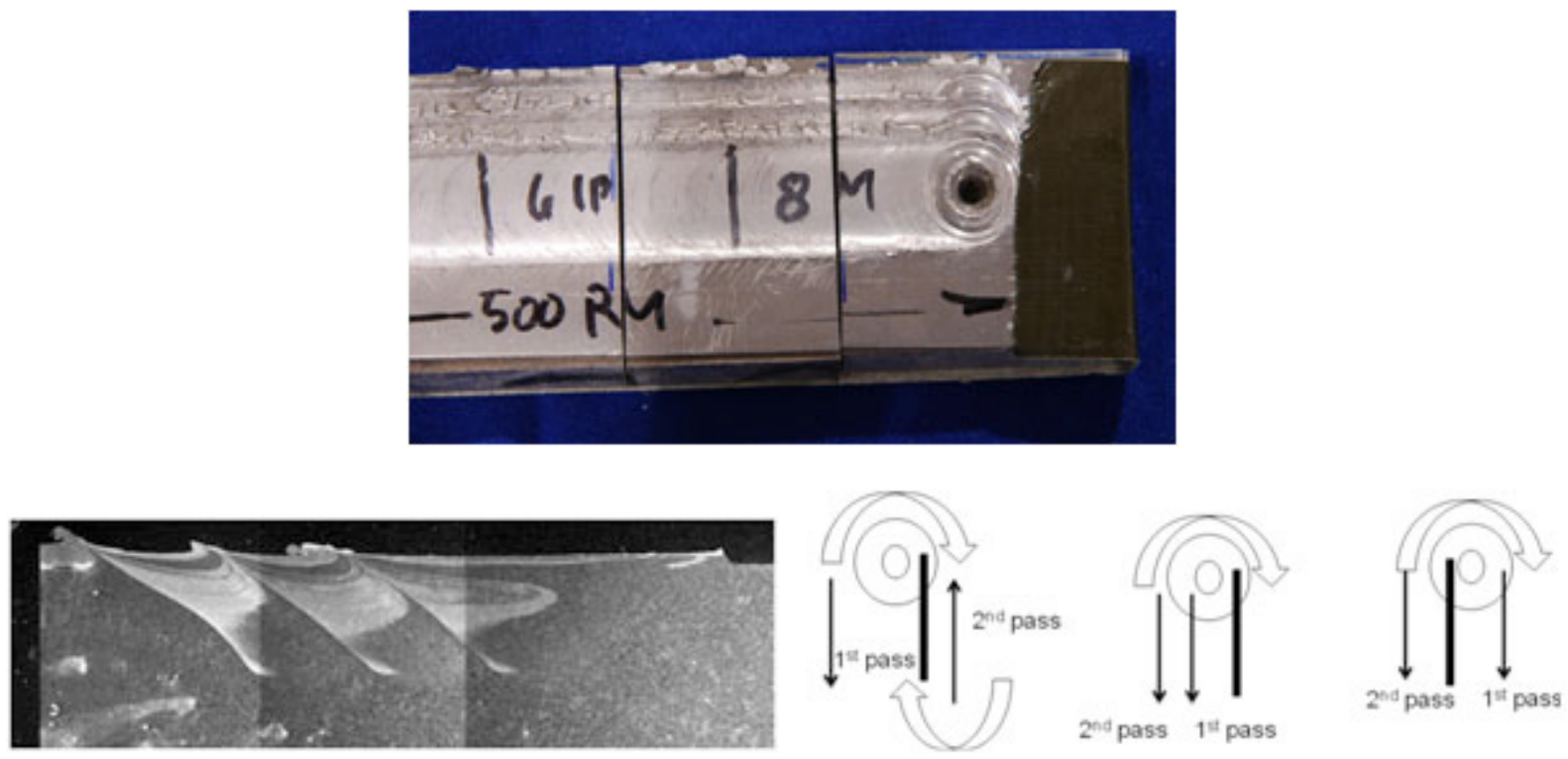

Figure 4.12. Illustration of Variables around Multipass FSP (Each successive pass can overlap the previous pass in different ways as determined by rotation direction and travel direction of the tool.)
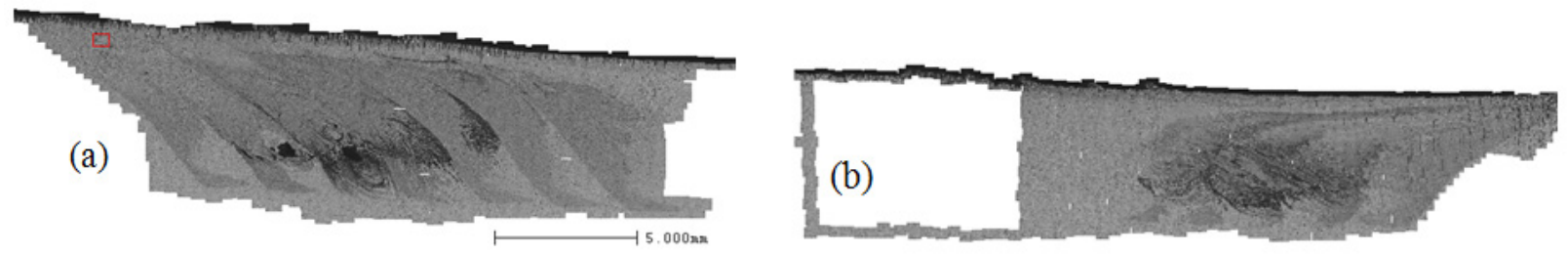

Figure 4.13. (a) Overlap Pattern that Consumes Retreating Side of Nugget and (b) Overlap Pattern that Consumes Advancing Side of Nugget

The rotation rate and travel speeds of the tool are also important influences on homogeneity of particulate distribution. During this project, several studies were undertaken to understand these variables and their fundamental effects on material flow and mixing. One result indicated that mixing of particulate is enhanced by using process parameters that allow the tool to rotate many times while covering some fixed distance. This is analogous to thread pitch on a screw. In the case of FSP, the quantity varied is advance per revolution (APR), or how far the tool travels laterally during each rotation. To improve the degree to which a particle is mixed with a base material, the tool needs to travel slowly and rotate quickly so more plastic work is introduced to the base material for each unit length of tool travel.

Figure 4.14 through Figure 4.17 illustrate the effects of decreasing APR. FSP takes place by shearing and deforming small slices of material from the front of the tool and moving them to the back. As the tool progresses forward, these slices are forged together, leaving behind a characteristic spacing between bands of material. The bands are defined by alternating regions of differing grain size and grain boundary angle that are the result of varying amounts of shear, recrystallization, and grain growth in each band. Lower APR produces thinner banding, reflecting the greater number of slices sheared per inch of travel. The number of slices per inch affects the degree of mixing and homogeneity attained in the processed 
region. Figure 4.14 shows a macrograph cross section of the processed region at the highest APR. Dark areas are rich in agglomerated nanotubes and contain open void space.

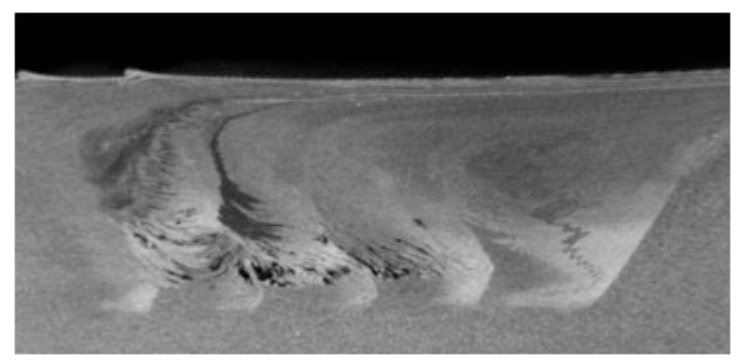

Figure 4.14. Processed Region at the Highest APR Showing Uneven Distribution of Nanotubes and Some Void Spaces

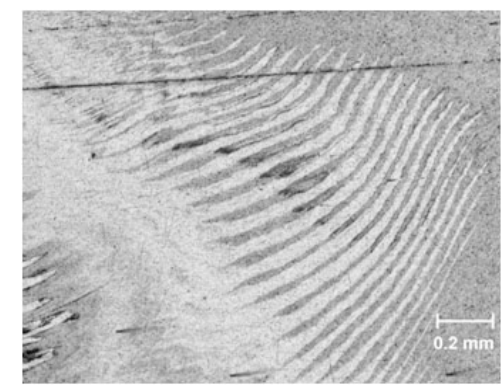

Figure 4.15. Higher Magnification View of Figure 4.14 Showing Relatively Wide Banding and Segmenting of Nanotube-Rich Areas (dark spots)

Figure 4.16 shows a cross-section macrograph of a processed region at very low APR. In this case, the processed region shows improved consolidation and less indication of visible agglomerated nanotuberich regions. At increased magnification (Figure 4.17), the processed region shows very fine banding and interleaving of the layers. From the perspectives of the agglomeration of nanotubes and weld consolidation, the very low APR parameters show much more promise for creating even distribution of nanotubes in the processed region.

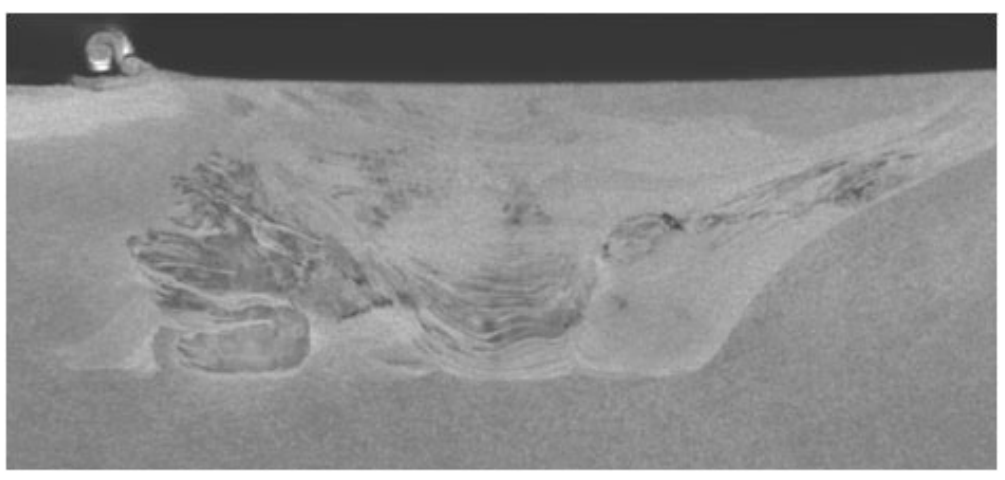

Figure 4.16. Processed Region at the Lowest APR 


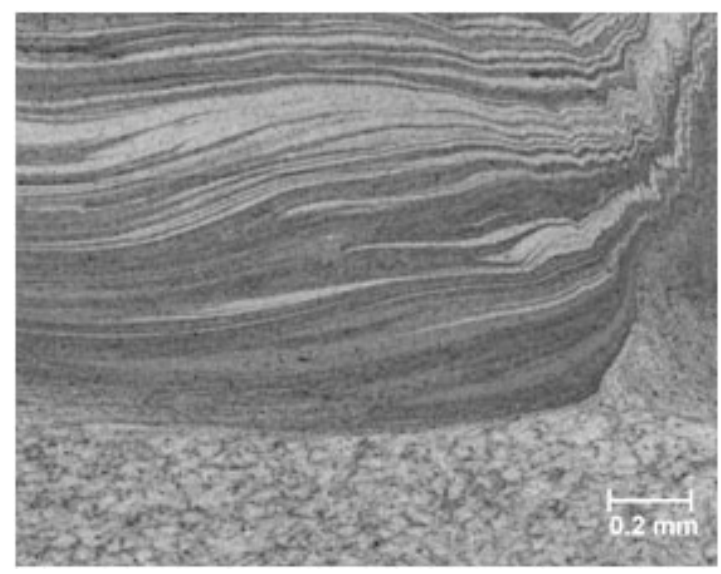

Figure 4.17. Higher Magnification View of Figure 4.16 Showing Fine Banding

One of the problems when dealing with nanoparticles (as opposed to micron-size particulate) is understanding when the process has led to a good particle distribution in the processed zone. In cases where the nanoparticulate is significantly agglomerated, the clumps are easily seen, but when nanoparticles are finely divided, they are not visible by optical methods. For best property improvement, it is anticipated that nanotubes dispersed well at the nanoscale will be important. One of the analytical techniques explored in this project to determine the fine distribution of nanotubes is Raman spectroscopy. Figure 4.18 shows the two distinctive peaks displayed by carbon nanotubes using Raman methods.

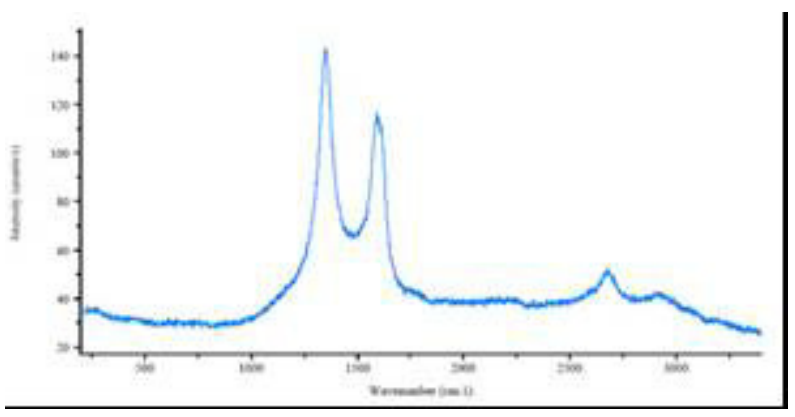

Figure 4.18. Characteristic Spectrum for Carbon Nanotubes in Raman Spectroscopy

This technique was used to determine whether or not nanotubes were present in a processed zone and to determine a qualitative sense of distribution by surveying numerous locations. Two samples were analyzed by these methods - a high APR case and a low APR case.

Figure 4.19 shows the results from the high APR case where there is more tool travel with each rotation, causing wider slices and less macroscopic mixing. The area survey indicated that when a dark area of agglomerated nanotubes was analyzed, the typical Raman pattern for nanotubes was observed. However, when areas away from the dark areas were analyzed, the spectra indicated almost no nanotubes were present. 

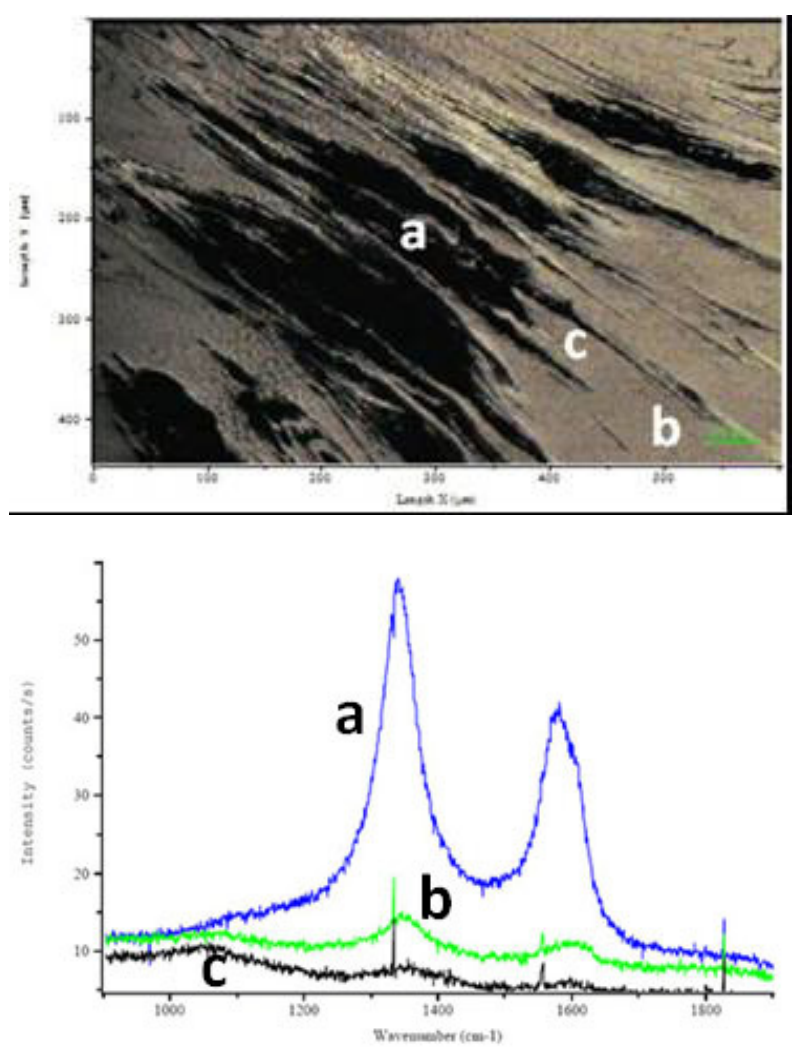

Figure 4.19. High APR Case-Nanotubes Occur as Agglomerates and Line Edges of Voids (areas away from agglomerates do not show significant Raman peaks.)

In contrast, Figure 4.20 and Figure 4.21 show a low APR case where better macroscopic mixing was observed. At fine scale, almost all areas surveyed show a robust nanotube signature, including lightcolored areas where no visible nanotube agglomerations could be seen. We interpret this data to indicate that low APR will produce the best particle mixing. 

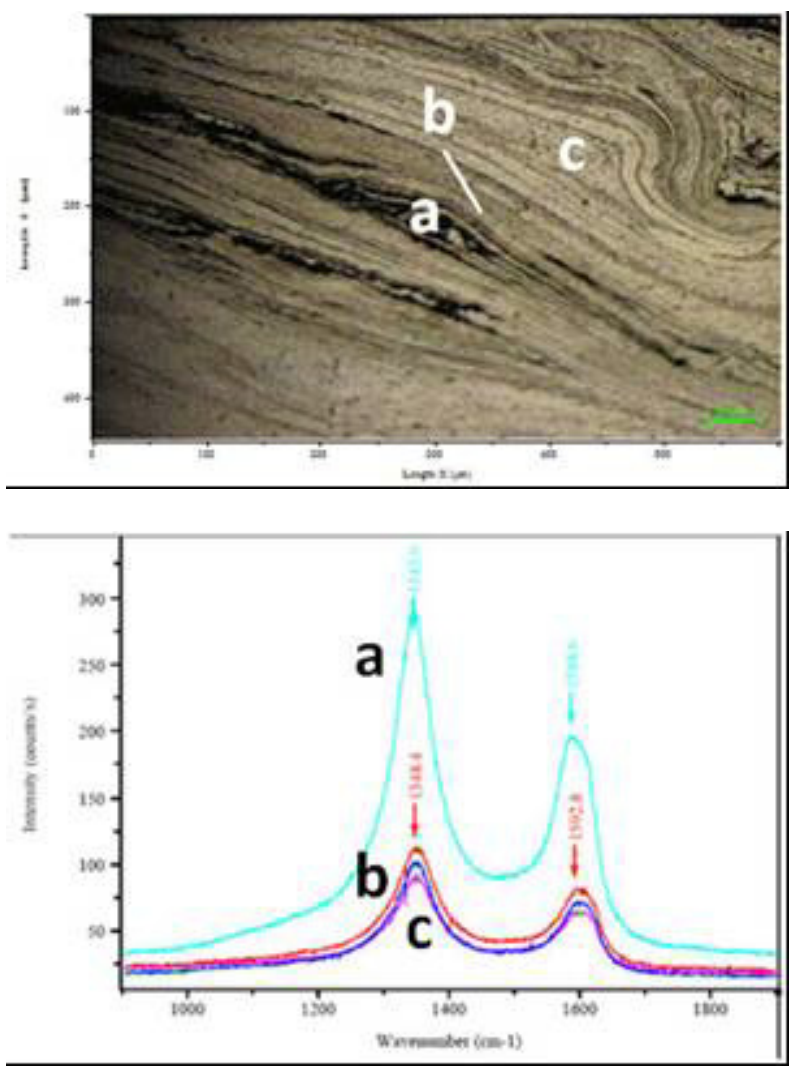

Figure 4.20. Low APR Case-Agglomerates are not as Pronounced (Better mixing, fewer voids, and Raman peaks indicate that nanotubes are present even in areas away from obvious concentrations.) 

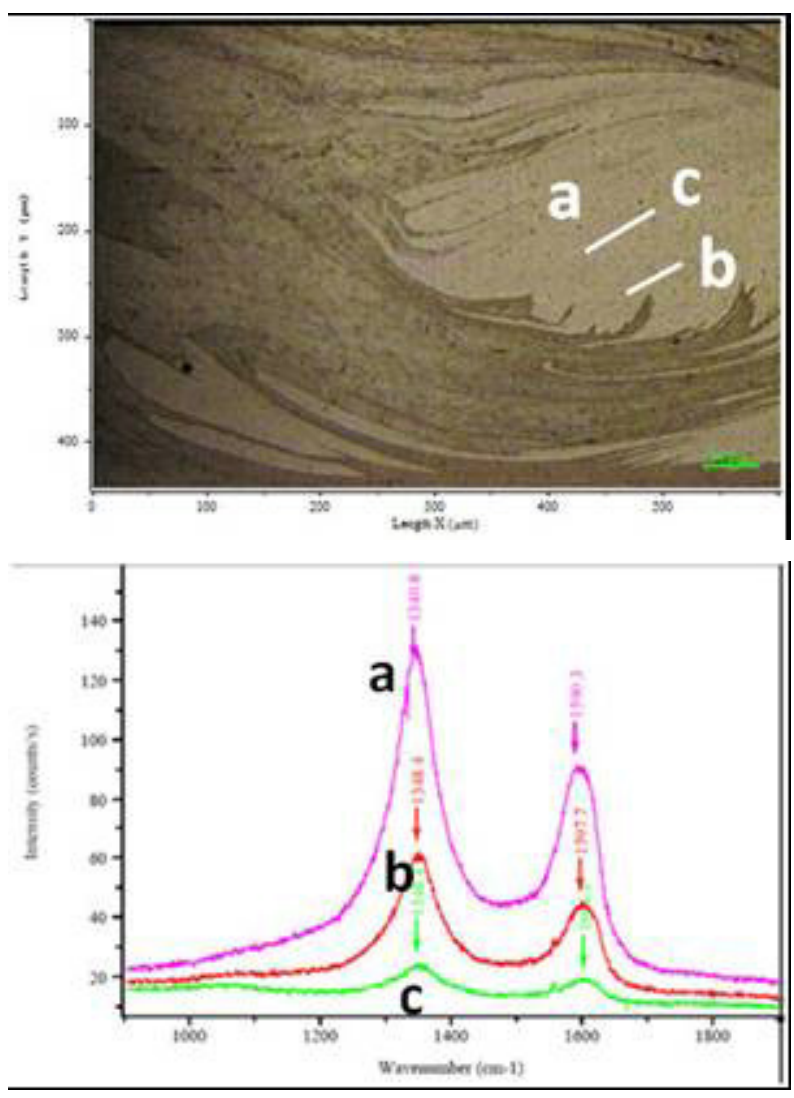

Figure 4.21. Low APR Case-Agglomerates are not as Pronounced (Better mixing, fewer voids, and Raman peaks indicate that nanotubes are present even in areas away from obvious concentrations.)

\subsection{FSP of Carbon Fibers}

During fiscal year (FY) 2010, two different carbon fibers, polyacrylonitrile (PAN) and graphite (GRPH), were used as reinforcements added into 6061 aluminum plates by FSP. Work in FY 2009 showed that the use of carbon nanotubes as reinforcements led to some agglomeration inside the processed region. Therefore, carbon fibers were selected for this study. It was believed that the much larger size of the individual carbon fibers would possibly reduce the problem of agglomeration. Two different carbon fibers were chosen in order to study their effect on the thermal conductivity and the mechanical properties of the processed region. In general, graphite fibers show significantly higher conductivity values compared to PAN fibers. On the other hand, PAN fibers are known for their better mechanical properties. The carbon fibers were added into the 6061 aluminum matrix by first cutting a number of grooves (1.0 in. long, $0.25 \mathrm{in.} \mathrm{wide,} \mathrm{and} 0.20 \mathrm{in.} \mathrm{deep)} \mathrm{along} \mathrm{the} \mathrm{length} \mathrm{of} \mathrm{the} \mathrm{aluminum} \mathrm{plate,}$ with a 0.10 in. spacing between adjacent grooves. This is shown schematically in Figure 4.22. After filling the grooves with continuous 1 in.-long carbon fiber woven strips, metal plugs made of 6061 aluminum were press-fitted into these grooves. Finally, the aluminum plate was subjected to FSP along the length of the grooves. Because the grooves were wider than the diameter of the friction stir tool pin, multiple passes were employed to create the processed zone. The aluminum plate was finally cross-sectioned perpendicular to the FSP run direction to study the distribution of the carbon fibers inside the process zone. 


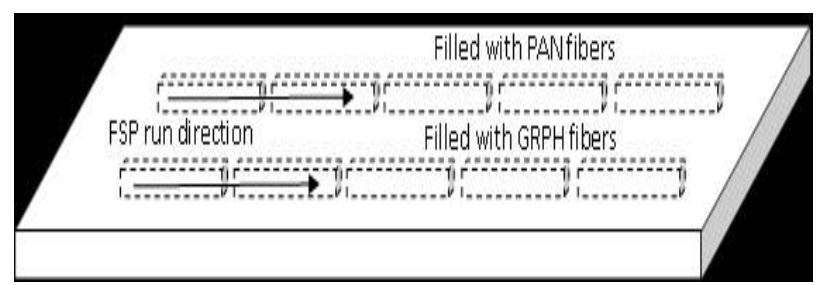

Figure 4.22. Schematic Drawing of the Technique Used for Reinforcing Aluminum Plate with Carbon Fiber

Cross-section images of both the PAN-filled and GRPH-filled grooves indicated the presence of large cavities inside the processed region. Figure 4.23a and Figure 4.23b show typical examples of PAN and GRPH fiber-filled processed regions, respectively. Cavities marked by arrows are visible on both the images. Also, a single-pass raster pattern of friction stir passes did not, in these studies, produce uniformly distributed carbon fibers at areas away from the large cavities. It can further be noted that the carbon fibers inside the processed region are distributed in a layered manner, which is indicative of the complex material flow during FSP. However, very limited mixing of carbon fibers is noted along the vertical direction. Because the initial trials left large cavities, some regions were reprocessed to fill those cavities. This was done by positioning the friction stir tool pin in the center of those cavities and then running along the entire length of the aluminum plate. Figure 4.24a and Figure 4.24b show cross-section images obtained from two separate locations along the PAN-filled reprocessed region. It is evident from both the images that the reprocessing technique led to a significant reduction of cavities inside the processed zone.
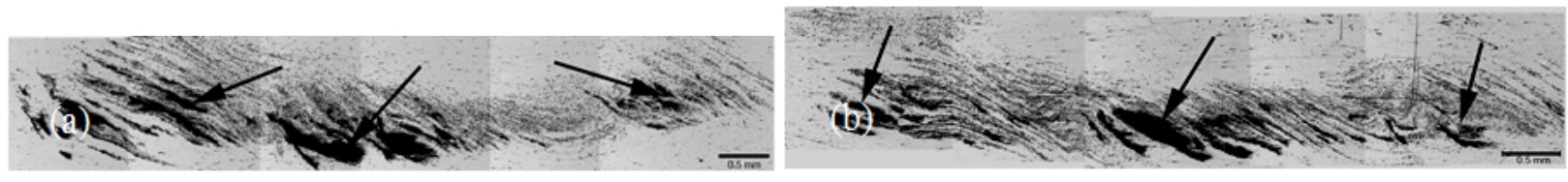

Figure 4.23. Cross-Section Images of the Process Region: (a) PAN-filled; (b) GRPH-filled

However, as shown by the arrow in Figure 4.24b, some porosity still remained even after the reprocessing runs. Moreover, after comparing Figure 4.24a and Figure 4.24b, it is noted that there is variability in carbon fiber distribution inside the process region along the length of the aluminum plate.
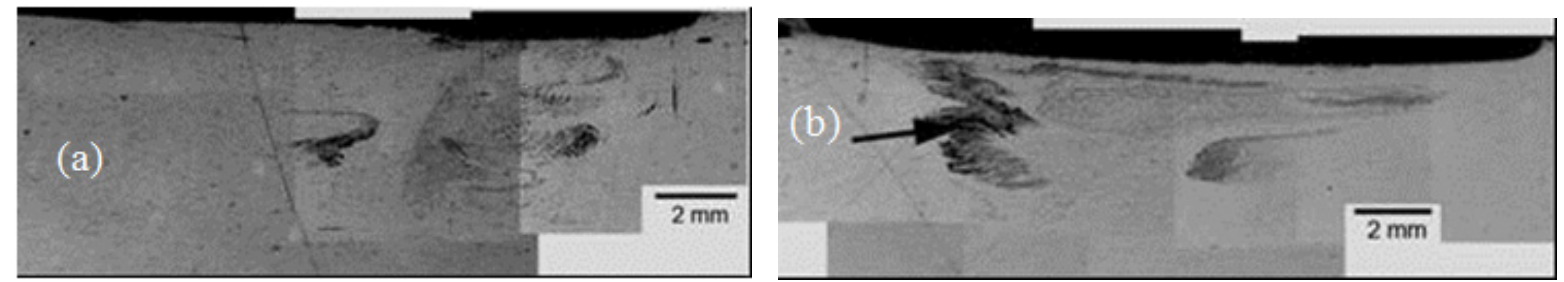

Figure 4.24. Cross-Section Images from the PAN-Filled Process Zone; $(a, b)$ : Low-magnification overviews of the process zone at two locations.

Higher magnification images from the reprocessed region showed that, in fine detail, the carbon fibers were broken and distributed in the aluminum matrix (Figure 4.25). The FSP process was able to chop the continuous carbon fibers into smaller sections. 

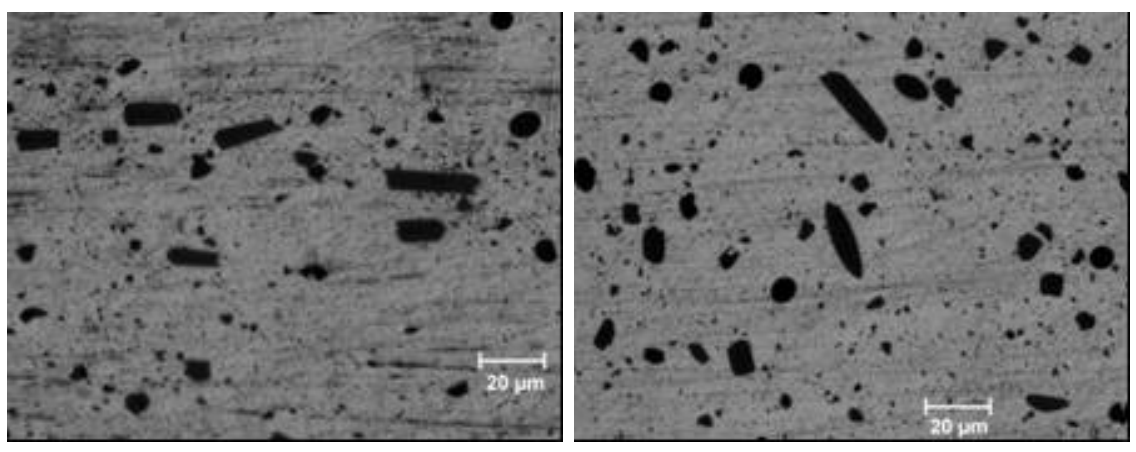

Figure 4.25. Higher Magnification Images from the Processed Zone Show the Fragmentation of the Individual Fibers, and Uniform Distribution Inside the Al Matrix

FSP resulted in random orientation of the carbon fibers inside the process zone. The size of most of the carbon fibers was found to be $\sim 10 \mu \mathrm{m}$, although a small fraction of carbon fiber fragments were noted to have significantly smaller or larger sizes than the average. Chopping of carbon fibers inside the process zone was confirmed by scanning electron microscope (SEM) images as well. Figure 4.26a shows a typical SEM image of the process zone after initial processing. Fragmentation of carbon fibers is evident in this image. The technical literature on aluminum-carbon fiber composites often reports presence of an aluminum-carbide reaction layer during manufacturing of carbon-fiber reinforced aluminum by melt processes. However, no such reaction layer was found in our work. Figure 4.26b shows a single carbon fiber embedded inside the aluminum matrix. The aluminum-carbon fiber interface in this image does not show any signs of the presence of a third phase.
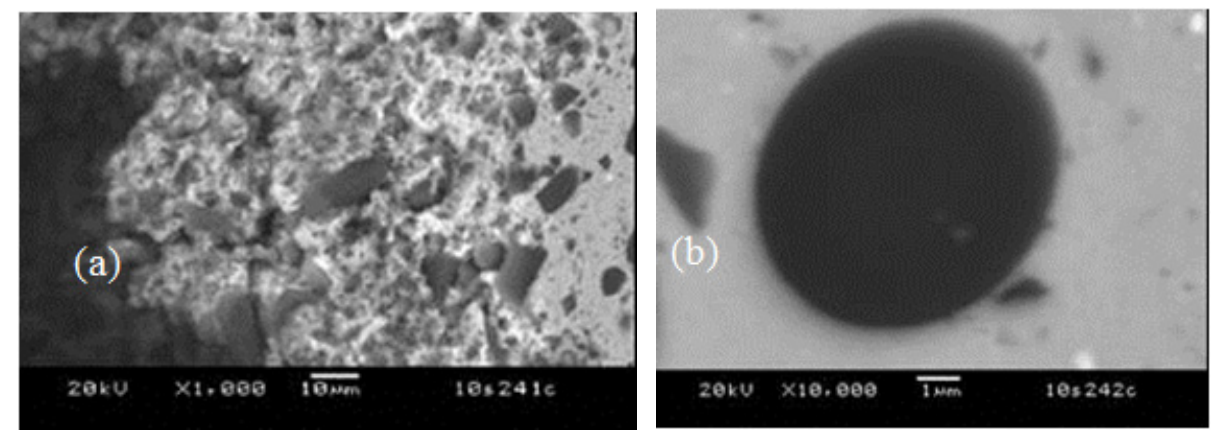

Figure 4.26. (a): SEM Image Showing Fragmentation of Carbon Fibers Inside the Process Zone; (b): Aluminum-Carbon Fiber Interface Without Aluminum-Carbide Reaction Zone.

To determine the effects of carbon-fiber reinforcements on the mechanical properties of the 6061 aluminum plate, hardness profile maps were generated. Microstructural examination of the process zone revealed a homogeneous distribution of carbon fibers at a few locations inside the aluminum matrix. Therefore, a hardness profile map should be able to indicate whether incorporation of carbon fibers resulted in the strength enhancement of the aluminum matrix, at least in those areas. A hardness profile map of a PAN-filled reprocessed section is shown in Figure 4.27. Considerable softening of the aluminum matrix can be observed inside the process zone. 


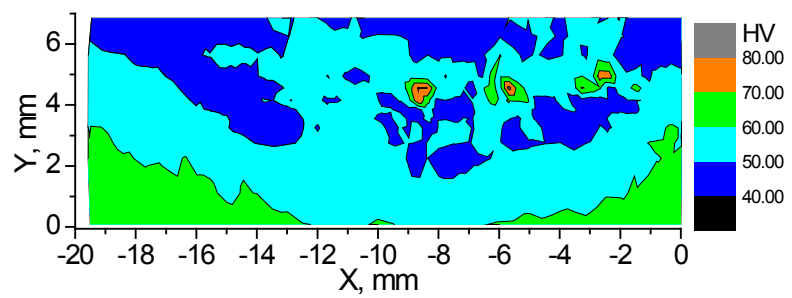

Figure 4.27. Hardness Profile Map of the PAN-Filled Reprocessed Section

The 6061 aluminum is a heat-treatable alloy; therefore, significant softening of the matrix occurred during FSP because of the associated multiple heating events. However, the presence of carbon fiber particles inside the process zone does not appear to have enhanced the hardness values. To eliminate the softening effects from repeated heating and cooling during FSP on the 6061 aluminum matrix, sections from both the PAN-filled and the GRPH-filled reprocessed material were given a T6 heat treatment. Hardness profile maps were then determined on the T6 temper sections. Figure 4.28a and Figure 4.28b show a hardness profile map and a macrograph of the profiled area from a PAN-filled cross section after T6 treatment, respectively. The hardness profile map has been superimposed on the macrograph for a better understanding the effects of carbon fiber on hardness. Significant strengthening of the aluminum matrix after the $\mathrm{T} 6$ treatment is evident from the hardness profile plot. However, areas of the crosssection that were carbon-fiber rich showed a lower hardness compared to the rest of the aluminum matrix. Because the average size of the chopped carbon fibers was $\sim 10 \mu \mathrm{m}$, significant strengthening of the aluminum matrix is not expected from their presence. We speculate that the lower hardness in the carbon-fiber-rich areas may be the result of the presence of subsurface porosity in and around the carbonfiber-rich areas.
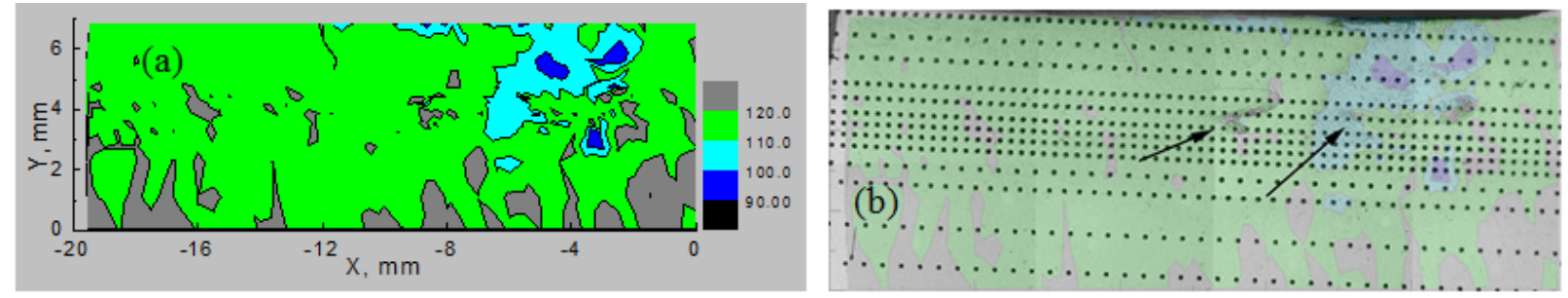

Figure 4.28. (a) Hardness Profile Plot for T6-Treated PAN-Filled Section; (b) Macrograph of the Profiled Section. Hardness map has been superimposed. Arrows indicate carbon-fiber-rich locations. It appears that incorporation of PAN carbon fiber did not result in any appreciable matrix strengthening.

The hardness profile plot from the GRPH-filled section is shown in Figure 4.29a, while Figure 4.29b shows the macrograph of the profiled section. Similar to the previous observation, lower hardness in carbon-fiber-rich areas is noted in the GRPH-filled section as well. It appears that incorporation of carbon fiber did not result in any appreciable matrix strengthening. The current FSP technique was able to chop the individual carbon fibers; however, the size of the chopped carbon-fiber particles is probably too large to offer any matrix strengthening effect. The effect of carbon-fiber particles on fatigue and toughness, however, may be different, but has not been tested yet. 

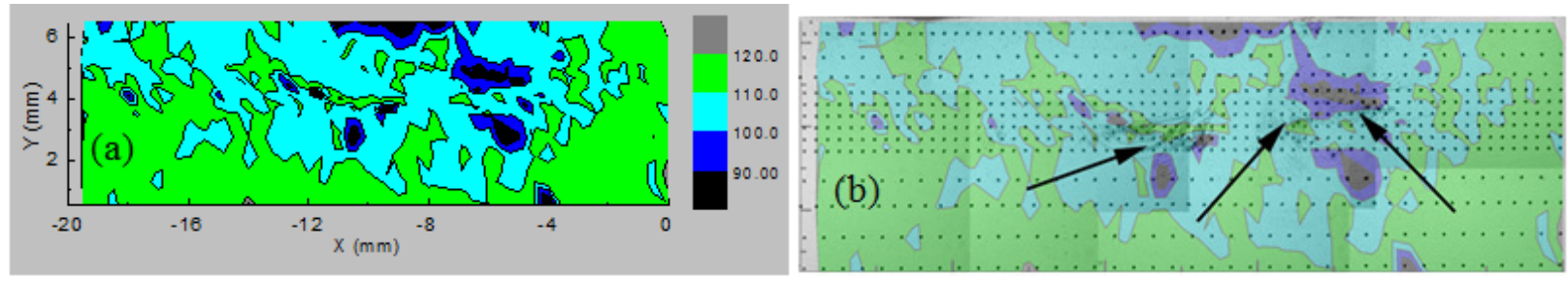

Figure 4.29. (a) Hardness Profile of T6-Treated GRPH-Filled Section; (b) Macrograph of the Profiled Section

The current study showed the presence of softer zones around carbon-fiber-rich areas. This is possibly related to the presence of porosity around the carbon-fiber-rich areas. The reprocessing technique used in the current study was able to close most of the large cavities. However, an appreciable amount of small porosity still remained in the process zone, which affected the mechanical properties considerably.

Samples from the process zone also were tested for thermal conductivity. For the thermal conductivity test, three aluminum samples from parent metal, seven PAN-filled samples, and seven GRPH-filled samples were tested. Thermal diffusivity was determined first from room temperature to $400^{\circ} \mathrm{C}$ using a laser flash technique specified in ASTM Standard E1461. Bulk density of the samples was then determined from the sample's geometry and mass. Finally, specific heat, $\mathrm{C}_{\mathrm{p}}$, was measured using differential scanning calorimetry. Thermal conductivity values were calculated as a product of these quantities (i.e. conductivity $=$ diffusivity $\times \mathrm{C}_{\mathrm{p}} \times$ density). The average bulk density of the various samples used in this study is summarized in Table 4.5 .

Table 4.5. Bulk Density (g/cc) of Samples in This Study

\begin{tabular}{ccc}
\hline $\begin{array}{c}\text { Parent } \\
\text { Aluminum }\end{array}$ & $\begin{array}{c}\text { PAN-Filled } \\
\text { Samples }\end{array}$ & $\begin{array}{c}\text { GRPH-Filled } \\
\text { Samples }\end{array}$ \\
\hline $2.69 \pm 0.003$ & $2.60 \pm 0.008$ & $2.61 \pm 0.026$ \\
\hline
\end{tabular}

Bulk density of both the PAN and GRPH samples are noted to be lower than that of the parent. Moreover, scatter in the density data also is high. Since bulk density of the carbon fiber $(2.25 \mathrm{~g} / \mathrm{cc})$ is less than that of $\mathrm{Al}(2.69 \mathrm{~g} / \mathrm{cc})$, both the PAN- and GRPH-filled samples should be lighter. A simple Rule of Mixtures calculation indicates around 20\% volume fraction incorporation in the carbon-fiber-reinforced samples. However, the microstructural analysis did not show any signs of such a high volume fraction of carbon fibers in the Al matrix. It is believed that the presence of microporosity around carbon-fiber-rich areas inside the process zone might be the other significant reason for the lower density of PAN or GRPH samples. Figure $4.30 \mathrm{a}$ shows the average measured thermal diffusivity data as a function of temperature. Thermal diffusivities for both the PAN- and GRPH-filled samples are found to be considerably lower than the parent. Moreover, the scatter in the data for PAN- or GRPH-filled samples is quite high. It is believed that the presence of porosity resulted in poor thermal diffusivity for both the carbon-fiber samples. Calculated thermal conductivity values as a function of temperature are shown in Figure 4.30b. 

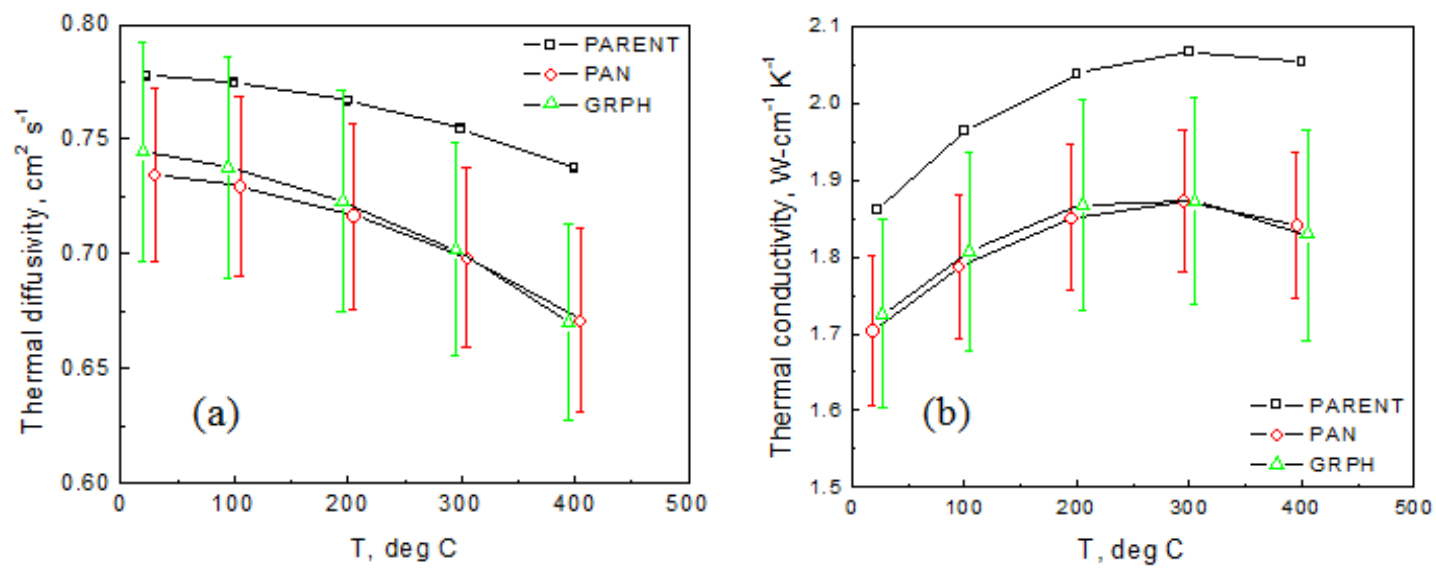

Figure 4.30. (a) Thermal Diffusivity vs. Temperature; (b) Thermal Conductivity vs. Temperature

\subsection{Summary of Carbon Fiber Work}

Carbon-fiber reinforcement of the aluminum matrix is possible by the current FSP technique. However, two major problems associated with the current technique are porosity around the carbon fibers and nonuniform distribution of chopped carbon fibers inside the process zone. It is believed that the grooves used in this study may be too large to be closed effectively. Use of smaller grooves or a different/larger friction stir tool may lead to better carbon-fiber distribution.

Use of carbon fiber as a reinforcement did not enhance the hardness of the matrix. This is an expected result, given the size of the chopped carbon fibers. However, lower hardness in carbon-fiberrich areas may indicate the presence of porosity. It is highly possible that the "true" effect of carbon fibers on hardness might have been masked by porosity.

Finally, incorporation of carbon fibers also did not improve the thermal properties. This is a surprising result, at least for the graphite carbon-fiber-filled samples. As discussed previously, the lower density of the carbon-fiber-filled samples is due to the incorporation of carbon fibers, and possible presence of porosity around carbon-fiber-rich areas. The presence of voids might have overshadowed the beneficial aspect of the carbon fiber on thermal properties, if any.

\subsection{FSP of steels}

This project also investigated FSP in steels. The tooling and process parameter space for accomplishing thick-section (up to 0.5 in. thick) FSP of steel materials was investigated. Much of the effort involved equipment development for induction pre-heating, and, more importantly, post-heating of the FSP region.

Steel and cast-iron FSP can require additional heat during the plunging phase of the processing run because drastic tool wear can occur when a cold tool is driven down into a cold substrate. In earlier work by PNNL and South Dakota School of Mines and Technology, induction heating of the plunge zone was found to be necessary to preserve the life of the tooling. Induction heating also was used to accomplish post-processing heating to effectively slow the cooling rates after processing. In fusion welding, it has 
been shown that in situ or trailing heating can significantly increase weld region ductility and affect the final microstructure, and may be able to positively affect fatigue performance as well.

Figure 4.31 shows a macrograph of a 0.5 in. thick processed area in low-carbon steel. Micrographs of the nugget region (Figure 4.31-bottom) and the parent metal (Figure 4.31-middle) show the microstructure is similar but with a large degree of very fine-grained acicular ferrite in the nugget of the processed zone. This microstructure may be especially favorable for fatigue life improvement. However, due to program constraints and a redirection to aluminum systems this concept was not tested in this project.
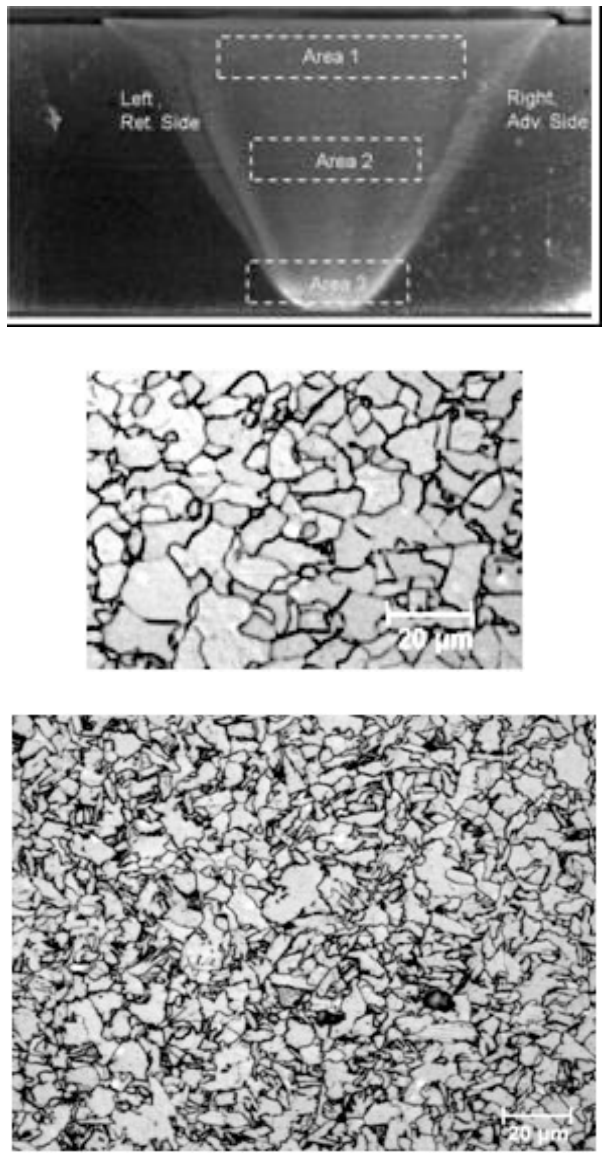

Figure 4.31. Macrograph of an FSP-processed Region in Low-Carbon Steel (top); Micrograph of Parent Material Microstructure (middle); Micrograph of Nugget Material from Area 2 Showing Fine-Grained Acicular Ferrite (bottom) 



\subsection{Part Prototyping-Piston Bowl Rim FSP}

In the latter part of this project, effort was made to locally modify the microstructure of the piston bowl rim area. The concept is illustrated in Figure 5.1. If FSP were applied to the area of a piston blank (prior to final machining) that will be the bowl rim area, then after final machining, the bowl rim will be composed entirely of fine-grained FSP nugget material that will possess improved fatigue performance. Adjacent areas of the piston will remain unmodified.
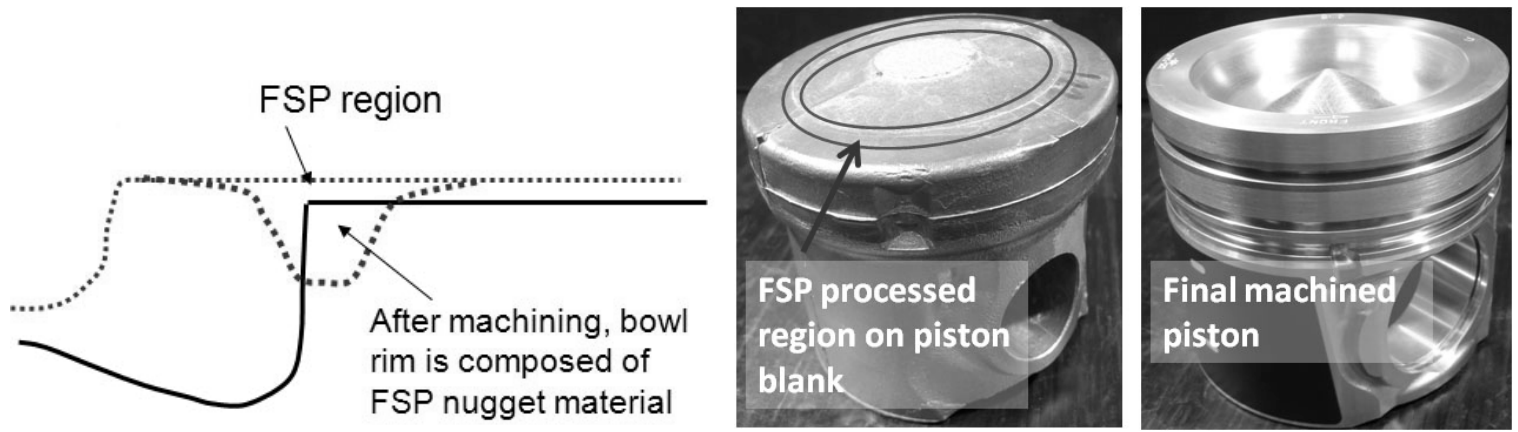

Figure 5.1. FSP Applied to Cast Piston Blank. (The area in the bowl rim after machining will be friction stir processed for improved microstructure.)

Work during FY 2010 demonstrated the techniques necessary for the practical application of FSP by demonstrating a circular "two-dimensional" processed region on a simulated piston top. Figure 5.2a shows the circular weld region and Figure 5.2b shows the machined final piston top with the processed region on the bowl rim. The processed region is fully consolidated and composed of a highly refined microstructure.
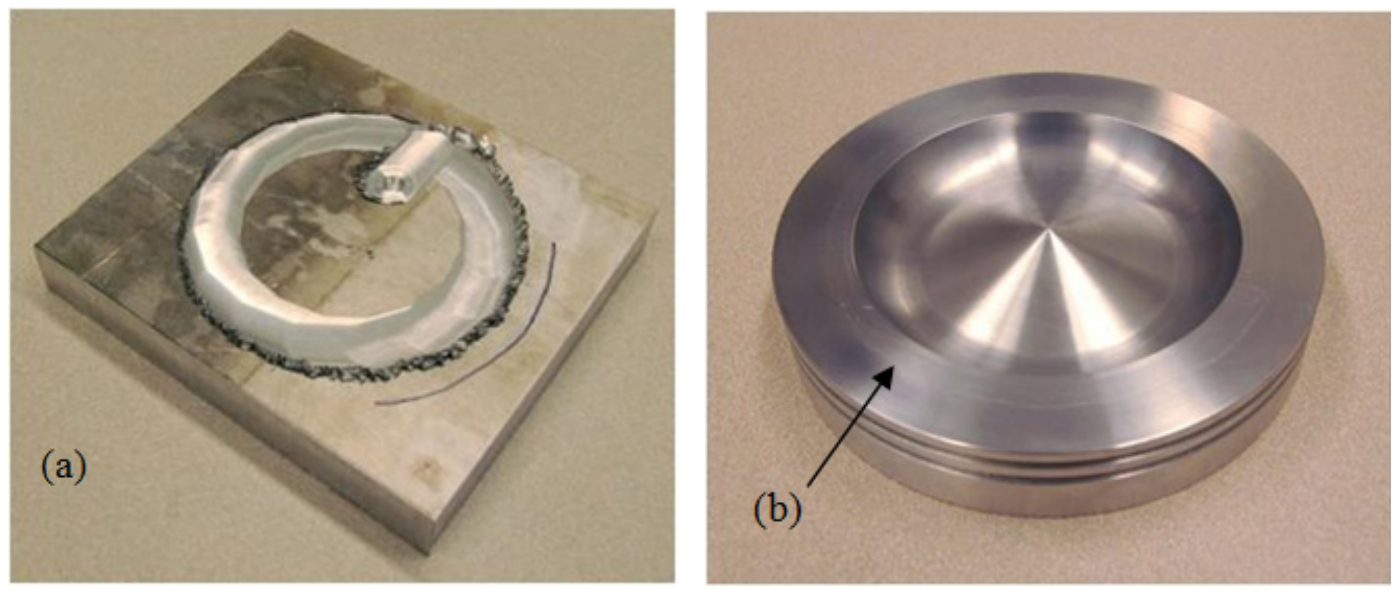

Figure 5.2. (a) Circular Process Region Created by "Welding" in a Counterclockwise Direction, then Turning to Center and Exiting Where the Piston Bowl Will be Located; (b) the Arrow Points Toward a Faint Line Demarking the Edge of the FSP Processed Zone on the Bowl Rim after Machining. 



\subsection{Conclusions}

The goal of this project was to develop friction stir processed components that can enable energyefficient combustion strategies, especially strategies that will require operation at higher PCP or higher temperature. FSP produces selected, graded structures that have shown increased strength and durability in fatigue. Surface modification through FSP may address some emerging material problems seen in very high combustion pressure systems such as HCCI engines. In addition, the process enables the incorporation of particulates into the surface, offering the potential to selectively modify the properties of materials to alter the thermal environment for increased thermal efficiency.

Experimental work to date on aluminum systems has shown significant increases in fatigue lifetime and stress-level performance in aluminum-silicon alloys using friction processing alone, but work to demonstrate the addition of carbon nanotubes and fibers into aluminum substrates has shown mixed results due primarily to the difficulty in achieving porosity-free, homogeneous distributions of the particulate. 



\subsection{Publications}

1. S. Jana, RS Mishra, JB Baumann, and G Grant. 2009. "Effect of stress ratio on the fatigue behavior of a friction stir processed cast Al-Si-Mg alloy.” Scripta Materialia 61(10):992-995. Accessed March 6, 2012 at http://www.sciencedirect.com/science/article/pii/S1359646209005168.

2. S. Jana, RS Mishra, JB Baumann, and G Grant. 2010. "Effect of friction stir processing on fatigue behavior of an investment cast Al-7Si-0.6 Mg alloy." Acta Materialia 58(3):989-1003. Accessed March 6, 2012 at http://www.sciencedirect.com/science/article/pii/S1359645409006946.

3. S. Jana, RS Mishra, JB Baumann, and GJ Grant. 2010. "Effect of Friction Stir Processing on Microstructure and Tensile Properties of an Investment Cast Al-7Si-0.6Mg Alloy." Metallurgical and Materials Transactions A, Physical Metallurgy and Materials Science 41(10):2507-2521. Accessed March 6, 2012 at http://www.springerlink.com/content/9345660847xx580m/.

4. S. Jana, RS Mishra, G Grant, J Baumann. 2010. "Effect of process parameters on abnormal grain growth during friction stir processing of a cast $\mathrm{Al}$ alloy." Materials Science and Engineering A, 528(1):189-199. Accessed March 6, 2012 at http://www.sciencedirect.com/science/article/pii/S0921509310009172

\subsection{Subject Inventions}

Invention Report filed by Caterpillar: File No: 09-724, "Friction Stir Processing for Aluminum 3rd Rail Application" 

PNNL-21262 


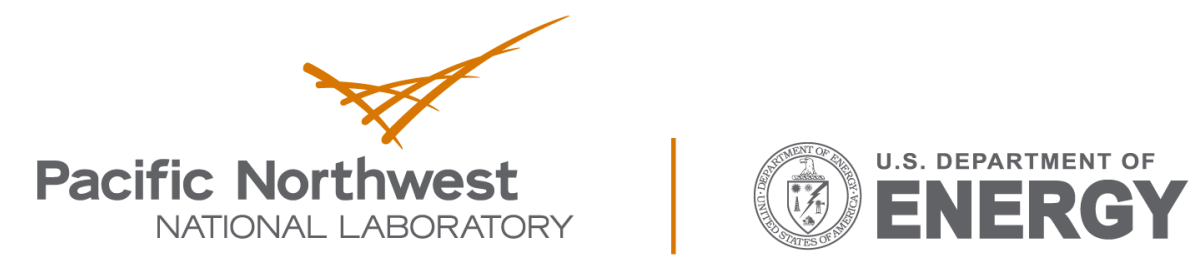

Proudly Operated by Battelle Since 1965

902 Battelle Boulevard

P.O. Box 999

Richland, WA 99352

1-888-375-PNNL (7665)

www.pnnl.gov 